\author{
POLINIZASTAB \\ ENTRMÓFILA EM CAJUEIRD \\ (Amacardium occiddentale L - ) \\ NQ LITQRAL DE PACAJUS-CE \\ FRANCISCO DEOCLECIO GUERRA PAULINO \\ Engentheiro Agrônomo
}

Orientador: Prof. Dr. LUÍs CARLoS MARCHINI

\begin{abstract}
Dissertaçăo apresentada à Escola Superior de Agricultura "Luiz de Queiroz", da Universidade de Sao Paulo, para obtenção do titulo de Mestre em Ciências. Area de Concentraçå: Entomologia. '
\end{abstract}

\author{
PIRACICABA \\ Estado de Sáo Paulo - Brasil \\ Dezembro - 1992
}


Ficha catalografica preparada pela segado de Livros da Divisăo de Biblioteca e Documentacăo - FCLR/USF

Paulino, Francisco Deoc lécio Guerra

P328p Polinização entomófila em cajueiro (Anacardium occidentale L.) no litoral de Pacajus-CE. Piracicaba, 1992.

$70 \mathrm{p}$.

Diss. (Mestre) - ESALQ

Bibliografia.

1. Abelha em caju - Polinização - Pacajus, CE 2. Caju - Po linização - Pacajus, CE I. Escola Superior de Agricultura Luiz de Queiroz, Piracicaba

CDD 634.573

582.0463 


\section{POLINIZAÇđ̃ ENTOMÓF ILA EM CAJUEIRO}

(Anacardium occidentale L.) NO LITORAL DE PACAJUS-CE

Autor: Francisco Deoclécio Guerra Paulino

Comissåo julgadora:

Prof. Dr. Luis Carlos Marchini

ESALQ/USP

Prof. Dr. Sinval Silveira Neto

ESALQ/USP

Profa Drạ Regina H. Nogueira Couto

:UNESP/Jaboticabal

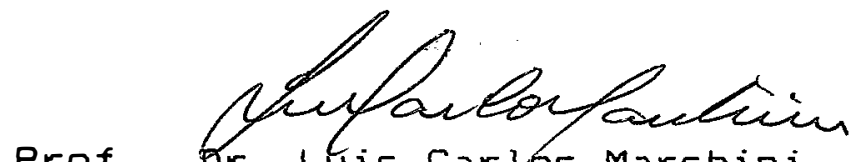

Prof. Or. Luis carlos Marchini

Orientador 
OFEREÇO

A JULL IO CESAR CAMPOS

(in memorian) por tudo que fez;

A meU pai ANTONIO PALLI INO

A minha mae GILDETE;

A mintia sogra ADALGISA

Aos meus irmaัos.

A minha esposa állarea e

a meUs filhos DIEGO e LUCAS,

objetivo maior dessa realizacra,

DEDICO. 


\section{AGRADECIMENTOS}

Ao Dr. Luis Carlos Marchini, professor do Departamento de Entomologia da ESALQ/USP, pela orientaçao e estimulo na realizaçao desta pesquisa;

Ao. Dr. Levi de Moura Barros, do Centro Nacional de Pesquisa do Caju, EMBRAPA/CNPCa, pelas valiosas sugestues;

Aos professores do Departamento de Entomologia da ESALQ/USP, pelos ensinamentos recebidos;

Aos professores Dr. Sinval Silveira Neto e Dr. Roberto Antonio Zucchi do Departamento de Entomologia ESALQ/USP e a professora Dra Vera Ligia Letizio Machado do Departamento de Zoologia do Instituto de Biociencias da UNESP-Rio Claro - Sao Paulo, pela identificaçao dos insetos;

Ao professor Dr. Evâneo Berti Filho do Departamento de Entomologia da ESALQ/USP, pela elaboraça do "Summary";

A Universidade Federal do Ceará (UFC), pela oportunidade de realizaçăo do Curso de Pós-Graduaça e a CAPES pela concesszo da bolsa;

Aos professores do Departamento de Zootecnia da UFC José Adalberto Gadêlita, Pedro Z. de Souza e Raymundo Mauro Araripe pelo estimulo e consideraçăo;

Ao Centro Nacional de Pesquisa do Caju, EMBRAPA/CNPCa, na pessoa do. Dr. Joaro Pratagil Pereira de Araújo; 
Aos pesquisadores da EMBRAPA/CNPCa, Dr. Adroaldo Guimaraes Rossetti e Ervino Bleicher, pela inestimável colaboraçă

A professora Drä Marisa A. d'Arce e à estagiária Erika Maria Roel, do Departamento de Ciências e Tecnologia Industrial da ESALQ/USP, pela valiosa colaboraça;

Aos meus cunhados, Roberto Morse, Jorge Washington, Aracy, Alcegisa, Adalci, Agicilda e aos meus concunhados Heliomar Sampaio e Aristides pelo estimulo e consideraçă

Aos funcionários da EMBRAPA/CNPCa Roque $e$ Williams pelo auxilio nas coletas de dados;

Aos colegas Renato Arleu, Sônia, Mauricio e Nélitan pelo incentivo;

Aos Engenheiros Agronomos Antonio Roberto Barreto de Melo e Raimundo Nonato Távora Costa, pelo incentivo e apoio;

As bibliotecárias Kátia M.P. Andrade e Eliana M.G. Sabino, pela eficiente revisao das referencias bibliográficas;

Aos colegas do curso de Pos-Graduaça em Entomologia, pelo companheirismo;

A todos que direta ou indiretamente, contribuiram para a realizaçao deste trabalho. 


\section{SUMÁRIO}

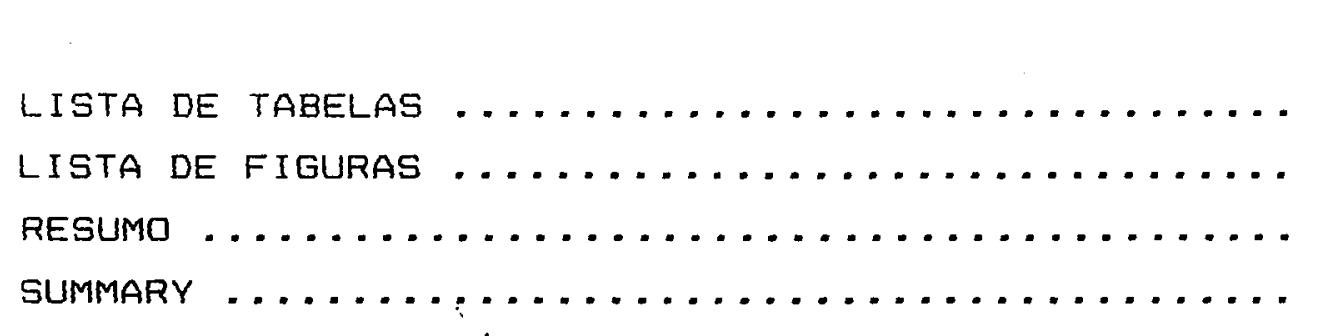

Página

viii

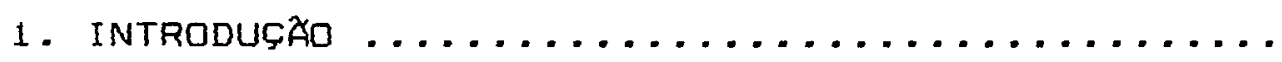

2. ReVisăo de literatura ..................

2.1. Q cajueiro (Anacardium occidentale L.) ...

2.2. o cajueiro no Brasil ...............

2.3. Taxonomia, origem e dispersao ......... 09

2.4. Aspectos morfologicos .............. 10

2.5. Cajueiro do tipo comum ...............

2.6. Cajueiro do tipo anao precoce ..........

2.7. Alguns aspectos da biologia floral do ca-

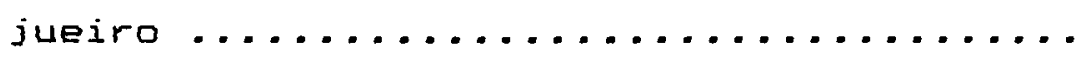

2.7.1. Inflorescencias e flores .........

2.7.2. Epoca de florescimento ..........

2.7 .3 . Antese ...................

2.7.4. Deiscencia da antera e receptividade do estigma ................

2.8. Importância da polinizaçao entomófila para - cajueiro ......................

3. material e metodos ...................

3.1. Localizaçao do Campo Experimental de Pacajus (CEP) ......................

3.2. Caracterizaçå da area experimental ..... 
3.3. Testes de polinizaçă em cultura de ca-

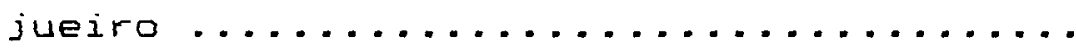

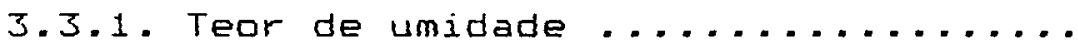

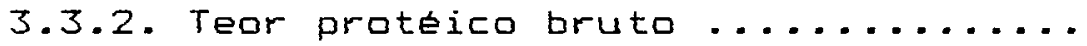

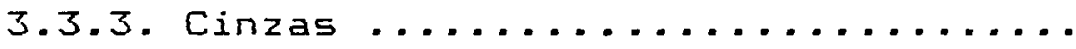

3.3.4. Teor de aleo ................

3.4. Análise estatistica ................

4. REsultados E discussão .................

4.1. Teste de polinizaçăo ...............

4.4.1. Insetos visitantes ............

4.1.2. Horário e número de visitas ......

4.1 .3$. Duraça das visitas ............ 53

4.1.4. Número de frutos fixados ......... 54

4.1.5. Peso dos frutos .............. 58

4.1.6. Composiça centesimal dos frutos... 60

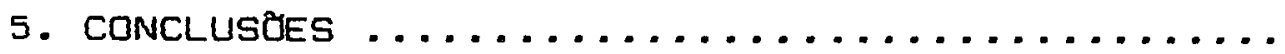




\section{LISTA DE TABELAS}

TABELA NO

Pagina

1 Parámetros climáticos médios do Campo Experimental de Pacajus-CE (EMBRAPA, 1990) .

2 Caracteristicas fisicas e quimicas dos so105 ; valöres medios nos horizontes superficiais (AP) e subsuperficiais (B2T ou C)

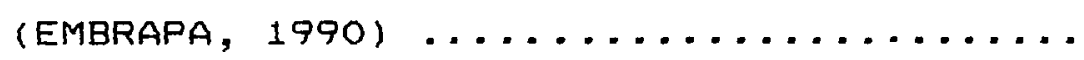

3 Taxons captirados nas paniculas de cajueiro anao-precoce no periodo de agosto a setembro. Pacajus (CE), $1991 \ldots . . . . .$.

4 Fontes de variaçăo, graus de liberdade (GL), quadrados médios (GM) e significância para número (NU) e duraça das visitas (DV) de abelhas as paniculas de cajueiro ango-precoce, clone CCP-Ob. Pacajus (CE), 1991

5 Medias do número e duraçaro de visitas (s) de abelhas (Apis mellifera L.) as paniculas de cajueiro no clone CCP-Ob, em diferentes horários. Pacajus (CE), 1991 ....:

6 Fontes de variaçao, graus de liberdade (GL), quadrados medios (QM) e significancia para número de frutos fixados por paniculas ensacadas e năo ensacadas de dois clones de cajueiro-anao-precoce. Pacajus,

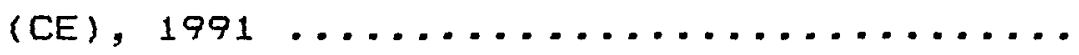


7 Análise conjunta dos dois experimentos, entre os periodos de avaliaça e da proteça das paniculas de cajueiro-anao-precoce, sobre a variável número de frutos fixados. Pacajus (CE), $1991 \ldots . . . \ldots \ldots \ldots$

9 Médias do número de frutos fixados em paniculas nao ensacadas e ensacadas em dois clones de cajueiro anzo-precoce.

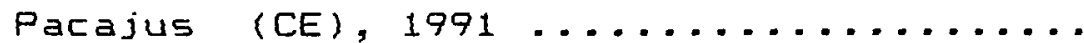

9 Analise da variância do peso (g) de frutos oriundos de paniculas ensacadas e não ensacadas de cajueiro-anao-precoce. Paca-

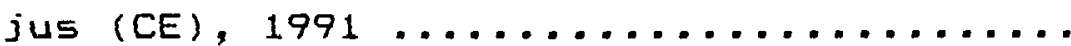

Medias do peso (g) dos frutos oriundos de paniculas ensacadas e nao ensacadas de dois clones de cajueiro-anao-precoce. Pacajus (CE), $1991 \ldots \ldots \ldots \ldots$

11 Composiğo centesimal (\%) de amêndoa de castantia de cajueiro-ană-precoce "in natura" oriundas de paniculas ensacadas, e nao ensacadas de dois clones de cajueiro

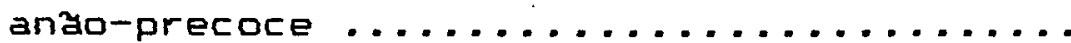




\section{LISTA DE FIGURAS}

FIGURA N므

Página

1 Medias do número de visitas de abelhas (Apis mellifera L.) as paniculas de cajueiro anao-precoce, do clone cCP-Ob em diferentes horários. Pacajus (CE), 1991

2 Médias de duraçăo das visitas de abel has (Apis mellifera L.) as paniculas de cajueiro ană-precoce, clone CCP-O6, em diferentes horários. Pacajus (CE), 1991.

3 Médias do número de frutos fixados em paniculas ensacadas e náo ensacadas de dois clones de cajueiro anao-precoce. Pacajus (CE), $1991 \ldots \ldots \ldots \ldots \ldots . . . . .$.

4 Medias do peso ( $g$ ) de frutos colnidos em paniculas ensadas e nao ensacadas de dois clones de cajueiro-anao-precoce. Pacajus (CE), $1991 \ldots \ldots \ldots \ldots \ldots \ldots \ldots . . . .$. 
POLINIZACÃO ENTOMÓFILA EM CAJUEIRO

(Anacardium occidentale L.) NO LITORAL DE PACAJUS - CE

Autor: Francisco Deoclecio Guerra Paulini Orientador: Prof. Dr. Luis Carlos Marchini

\section{RESUMO}

Objetivando-se estudar a polinizaça entomófila no cajueiro, desenvolveu-se o presente trabalho no Campo Experimental de Pacajus (CEP), EMBRAPA/CNPCa no periodo de julho à setembro de 1991. Utilizaram-se os clones CCP-Ob e CCP-76, sendo selecionadas 10 plantas para cada um, em delineamento inteiramente casualizado em esquema fatorial. Registraram-se as especies de insetos visitantes, o horário das visitas de abelhas do gênero Apis, o número de frutos fixados, o peso dos frutos de paniculas ensacadas e nao ensacadas e a análise centesimal da amêndoa. Os dados foram submetidos a análise da variância mostrando que Apis mellifera é a especie predominante entre as coletadas Palybia ignobilis, Brachygastra lecheguana, Camponotus 5p., Palybia 5p.; Zethus 5p., Palistes 5p.; Xylacopa (Neaxylocopa) grisescens, Xylocopa (Neaxylocopa) cearensis, Ornidia obesa e Dysdercus sp.); a menor fixaço de frutos ocorreu em paniculas ensacadas em relaçă as nao ensacadas (clone ccp-06 17,27 e 0,87, clone cCP-76 16 e 0,93, respectivamente; a duracao média de visitas de Apisé 10 segundos e o pico 
máximo de visitas ocorre entre $9 \mathrm{~h}$ e $14 \mathrm{~h} 30$; as paniculas nao ensacadas apresentaram frutos mais pesados em relaça as ensacadas (clone CCP-06 6,639 e 4,889, CCP-76 8,58g e 7,68g, respectivamente); o clone CCP-O6 apresentou maior variaça na composiçăo da amêndoa "in natura" com menores teores de dleo $(6,23 \%)$ e cinzas $(12,50 \%)$ e maiores teores de proteina bruta $\{8,21 \%)$ e carboidratos $(6,32 \%)$ nas paniculas ensacadas em relaçă às nåo ensacadas. 
ENTOMOPHILOUS POLLINATION ON CASHEW TREE

(Anacardium occidentale L.) CostLAND OF PACAJUS, STATE OF CEARA, BRAZIL

Author: Francisco Deoclécio Guerra Paulino Adviser: Prof. Dr. Luis Carlos Marchini

GUMMARY

This research deals with the entomophilous pollination on cashew tree. The experiments were carried out in the Experimental field of Pacajus (EMBRAPA/CNPCa), State of Ceara, Brazil, from July to Semptember 1991. The clones CCP-O6 and CCP-76 were utilized, by selecting 10 plants of each one, in a factorial totally randomized design. The following data were registered: species of visiting insects, the hourly visits of bees of the genus Apis, the number of set fruits, the weight of fruits from bagged and non bagged panicles, and the centesimal analysis of the nut. These data were submitted to the variance analysis. The results were as fallows: Apis mellifera is the predominant species among the ones collected (Polybia ignobilis, Brachygastra lecheguana, Camponotus 5p., Polybia 5p., Zethus sp., Palistes sp., Xylocapa (Neaxylocopa) grisescens, Xylocopa (Neoxylacopa) cearensis, ornidia obesa and Dysdercus sp.); the lowest setting of fruits occurred in the bagged panicles, when compared to fruits from non bagged panicles (clone CCP-06 17 , 
27 and 0.87 , clone CCP-76 16 and 0.93 respectively; the mean duration of Apis visits is 10 secands and the highest peak of visits occurs between $9: 00$ and $11: 30$ a.m.; the non bagged panicles produced heavier fruits when compared to fruits from non bagged panicles (clone CCP-O6 6.63 and 4,88, clone CCP-76 8.58 and 7.68 , respectively); the clone CCP-O6 presented the highest variation in the composition of the nut "in nature, lower contents of oil and higher contents of crude protein in the bagged panicles, in relation to the non bagged ones, $48.2 \%$ and $51.4 \%, 30.35 \%$ and $28.00 \%$, respectively. 


\section{INTRODUÇÃ}

o cajueiro, planta eminentemente tropical disseminada em quase toda faixa intertropical terrestre, como planta cultivada ou ná, e considerada pela maioria dos autores modernos que se dedicaram ao seu estudo, como sendo o litoral nordestino do Brasil, provavelmente, o centro de origem e dispersăo dessa frutifera.

Quando Ehegaram ao Brasil os colonizadores já encontraram-no amplamente disseminado na faixa litorãnea, conforme se tem noticia e atestam as primeiras citaçoses a seu respeito. Por outro lado praticamente todas as especies descritas do gênero Anacardium sào originárias dó 'continente americano excetuando-se apenas quatro delas (A. Caracolii, A. encardium, A. excelsum e A. rhinocarpusl que nå så encontradas no Brasil.

Embora o nordeste brasileiro nao seja a regia que encerra o maior número de especies do gênero, tem sido considerada a regizo onde A. occidentale apresenta maior 
diversidade e adaptaçao, com uma grande variedade de tipos dentro da especie, com relaçăo ao porte, hábito de crescimento, coloraçăo e tamanho das folhas, frutos e pseudofrutos (pedúnculo).

A cajucultura encontra-se disseminada em quase todos os estados do pais concentrando-se na regiao nordeste a maior produçă, onde ocupam lugar de destaque os estados do Ceará, Piaui, Rio Grande do Norte, responsáveis por 94,52\% da produçao nordestina (ANUÁRIO ESTATISTICO DO BRASIL, 1991).

Atualmente pode-se afirmar que o cajueiro ocorre numa área geograficamente compreendida entre as latitudes de 300 Norte e $31^{\circ} \mathrm{Sul}$, em grande número de paises e em muitos dos quais acha-se perfeitamente aclimatado. Vale ressaltar que inequivocamente o homem foi o mais eficiente agente de dispersaro dessa cultura, tanto do litoral nordestino para o restante do pais, quanto desse para as mais longinquas regieles onde hoje é cultivado.

o cajueiro é uma frutifera atualmente encontrada em grande parte do mundo tropical, todavia, em termos econamicos, sua forga maior concentra-se' na India, Brasil, Moçambique e Tanzânia. No Brasil a cultura encontrase disseminada em 20 Unidades da Federaça, contudo a regiăo nordeste, contribuiu com 99,98\% da produçæo nacional no ano de 1989, onde destacam-se os estados do Ceará, Piaui e Rio Grande do Norte, responsaveis por $94,5 \%$ da produça brasileira (ANUARIO ESTATISTICO DO BRASIL, 1991 ). 
o cajueiro é cultivado comercialmente para a obtenção da amêndoa da castanta ( $A C C$ ), do liquido da casca (LCC) e de produtos derivados do pedúnculo, como doces, sucos, aguardente, cajuina, licores, vinhos, além do relevante papel que a cultura exerce no tocante a absorça da mao-de-obra no meio rural e urbano por ocasiaro da safra.

Em termos de área cultivada, no Brasil, a regiao nordeste encerra mais de $98 \%$, sendo por ordem de importancia os estados do Ceara, Piaui e Rio Grande do Norte, os responsáveis por mais de $80 \%$ do cultivo. A expansaro da cultura nesses estados deveu-se principalmente as favoráveis condiçaes climáticas, existência de terras a baixos preços e concentraçues das fabricas de beneficiamento de castanha e pedúnculo. Estima-se que atualmente a área ocupada com a cultura, considerando-se a existência das formaçęes nativas e dos pequenos plantios, atinja 400.000 ha. A cajucultura e uma atividade econômica e social que alem de gerar divisas superiores a 110 milhoes de dólares, garante renda para mais de 800.000 pessoas anualmente (EMBRAPA, 1987).

- Brasil e o primeiro produtor' 'mundial de castanha, com 193.000 toneladas metricas (FAO, 1992) e segundo exportador de amêndoa de castanta e primeiro do liquido da casca. É também o pioneiro na industrializaça do pseudofruto, com mais de 30000 toneladas de sucos e significativo valume de doces e outros produtos que sao consumidos no mercado interno (EMBRAPA, 1987). 
Aproximadamente $90 \%$ do total produzido dos produtos da industrializaço da castanha de caju sao destinados ao mercado externo, sendo EUA o principal mercado consumidor, em virtude dos exportadores brasileiros preferirem o mercado americano pelas facilidades existentes nas transaçoes comerciais e a proximidade entre os portos do Nordeste e Nova York. Alem dos EUA, figuram camo consumidores - Canada, Paises Baixos, Alemantha, Austria, Africa do Sul, França e outros, cuja participaçao năo atinge $5 \%$ do volume de exportação.

Apesar da importância econômica da cajucultura, notadamente na regiao nordeste, a rendimento medio anual sofreu um considerável decréscimo no intervalo compreendido entre as safras de $1974 / 1975$ e 1977/1988, apresentando atualmente um rendimento medio de $240 \mathrm{~kg}$ de castanha por hectare contra aproximadamente $740 \mathrm{~kg}$ obtido na safra $1974 / 1975$ (EMBRAPA, 1990).

Atualmente há uma preocupaçăo constante das entidades de pesquisa, industrias e cajucultores no sentido de rever a estrutura de produça e retomar a créscimento do rendimento da cultura para tornála mais rentável no decorrer dos próximos anos. Para isso é necessário que se faça uma análise dos fatores intrinsicos e extrinsicos, responsáveis pelos baixos rendimentos. Dentre os fatores intrinsicos a participaçao dos insetos como agentes polinizadores deve ser visto como um provável fator de aumento de produtividade da 
cultura. Esses vegetais que apresentam estruturas anatomicas adequadas à polinizaça cruzada tem a possibilidade de mostrar algumas vantagens como a quebra da frequência genetica, permitindo assim novas combinaços de fatores hereditários, o que poderá redundar no aumento de produçao de frutos e sementes.

A polinizaço ineficiente do cajueiro provavelmente seria uma das causas da baixa produtividade da cultura segundo DAMODARAM et al., 1966. Por outro lado FREE \& WILLIAMS (1976) verificaram a importancia positiva dos insetos polinizadores do cajueiro, afirmando que por uma razao ou outra as plantas menos produtivas sao menos atrativas para os insetos do que as mais produtivas.

Considerando-se a grande expressao econâmicosocial da cultura na regiao nordestina, especialmente no litoral cearense, e segundo BARROS (1988a) a participaçao dos insetos como agentes polinizadores é notável nessa regiao, destacando-se as formigas pretas e abelhas. O presente trabalho foi desenvolvido na micro regigo Litoral de Pacajus, onde encontra-se implantado o Centro Nacional de Pesquisa do Cajú - CNPCa da EMBRAPA e teve como objetivas:

- coletar os exemplares de insetos visitantes das paniculas e sua identificaço para um melhor conhecimento das especies de maior interesse;

- verificar o efeito do impedimento de visitas de insetos as paniculas na fixaçăo de frutos; 
- registrar os horários de maior ou menor visitaçao dos insetos durante quatro periodos estabelecidos no decorrer do dia;

- determinar dentro dos periadas estabelecidas - número de visitas de insetos as paniculas;

- observar e determinar com relaço aos periodos referidos anteriormente a duraçao das visitas de abelhas do gênero Apis por se tratar de uma especie entre os polinizadores bióticos que desperta maior interesse para as culturas de um modo geral;

- determinar a media de peso dos frutas (castanhas) fixados e desenvolvidos em inflorescências ensacadas e nao ensacadas;

- determinar a media do número de frutos fixados em paniculas ensacadas e nao ensacadas;

- determinar os teores de cinza, oleo, proteina e carboidratos dos frutos fixados e desenvolvidos nas paniculas ensacadas e năo ensacadas. 


\section{REVISÃO DE LITERATURA}

2.1. O cajueiro (Anacardium accidentale L.)

o cajueiro, planta provavelmente originaria do Brasil, está hoje disseminada na maioria dos paises tropicais do mundo. Cerca de $82 \%$ da sua produça está restrita a Índia, Brasil, Tanzânia, Quênia, Moçambique e Malásia, onde exerce destacável papel socio-econômico a nivel local, regional ou nacional, por se tratar de uma atividade geradora de recursos externos e absorver a mao-de-obra, na indústria e no campo (FAO, 1992). Outros paises como a Venezuela, Madagascar, República Popular do Benin, Costa do Marfim, Uganda, República Popular da China e Guatemala 'tambem são responsáveis pela exportaçå e industrializạ̧a da amêndoa da castanha (LOPES NETO, 1981).

Q cajueiro tem sido cultivado com a finalidade de obter-se a amendoa da castanha, porém para sua obtençao dois subprodutos de elevado valor săa obtidos, o liquida da casca e o pseudofruto. Pelo alto valor econômico que 
representam no Brasil, elevam cada vez mais o potencial de lucratividade da cultura e contribuem cada vez mais para consolidaçă da cajucultura.

Sequndo BARROS \& MELO (1987) a castantia de caju está incluida entre as nozes mais comercializadas no mundo. Isso deve-se ao seu alto valor nutritivo, a diversidade de formas como é consumida e a prefos que alcanca no mercado interno e externo o que desperta interesse na melhoria da forma atual de exploraça, nos paises maiores produtores e exportadores como Brasil e India.

\subsection{O cajueiro no Brasil}

A área ocupada pelo cajueiro no Brasil é aproximadamente de 500.000 ha, distribuidos entre várias unidades da federaço. No entanto e a regiao nordeste, notadamente 35 faixas litorâneas e de transică 1itoralsertăo dos estados do Ceará, Piaui e Rio Grande do Norte, que e responsável por $94,5 \%$ da produsăo brasileira, quando a produça total da regiăo atinge $99,98 \%$ da produçà nacional (ANUARIO ESTATISTICO DO BRASIL, 1991).

o Brasil vem alternando com a India a posicaro de primeiro lugar como produtor e exportador de amêndoas de castantia. E tambem o maior exportador do liquido da castantia e primeiro pais a industrializar o pseudofruto para a 
obtençăo de suca, o qual chega a 40 mil toneladas por ano comercializados internamente, alem de doces, compota, licor, cajuina, geleia, aguardente e autros. Embora o volume de produçao de pseudafruto produzido por ano seja em torno de 1 milhao de toneladas, apenas $10 \%$ é industrializado. o restante é desperdicado, embora possa ser reutilizado como fonte de alimento para as populaçaes mais carentes e até mesmo como alternativa na merenda escolar da regiao (LIMA, 1988).

\subsection{Taxonomia, origem e dispersao}

o cajueiro, pertence ao gênero Anacardium da familia Anacardiacea, sendo esta composta por cerca de 60 a 70 gêneras e de 400 a 600 especies. Entre estas a manga (Mangifera indica), o pistache (Pistacia vera) e as especies do gênero Spondia (cajá, seringuela, umbu, cajámanga) sao bastante conhecidas na America tropical (JOHNSON, 1974; PURSEGLQVE, 1974).

A respeito da origem do cajueiro as iafirmaçoes sao baseadas em provas circunstanciais que o Brasil, ou senao pelo menos a Norte da America do Sul e parte da America, seja presumivel centro de origem da especie. Por outro lado comparando-se as informaçoes disponiveis com as evidencias relacionadas por HARLAN \& WET (1973), há de convir-se que a maioria aponta o Brasil como provável centro de cultivo desta 
frutifera, muito embora há ausência de informaças conclusivas relacionadas com o atual estágio de domesticaçăo. Certo é que a especie apresenta caracteristicas diferenciadas daquelas presentes nas outras especies do gênero (MaTA, 1982; BARROS, 1987 E LIMA, 1988).

Entre as espécies existentes no gênero, a Anacardium occidentale e a única cultivada e a de maior expressão do gênero (MORTON, 1961; JחHNSON, 1973; e MITCHELL \& MORI, 1987). MITCHELL \& MORI (1987), no entanto, alertam para o fato de que a distribuicaro natural da especie é totalmente confundida com a dispersao por cultivo. A regiao Amazânica é o principal centro de diversidade do gênero, e em segundo a planalto central brasileiro (regiao de cerrados) embora a especie possa ser encontrada nos cerrados, na Amazonia, em vegetaça de restinga, em vegetaça de caatinga e no nordeste brasileiro.

\subsection{Aspectos morfológicos}

- cajueiro é uma frutifera perene que apresenta ramificaçôs baixas, cuja altura atinge em média cinco a oito metros, podendo as vezes, encontrar plantas com ate 15 metros. Sua copa tem forma de guarda-chuva, com ramificaçoes atingindo o solo. Possui envergadura media entre 12 a $14 \mathrm{~m}$ podendo ser superior a $20 \mathrm{~m}$. As folhas 5 ao 5 imples, 
inteiras, alternadas, com aspectos subcoreaceos, peciolados e sem pelos, com comprimento que varia de 10 a $20 \mathrm{~cm}$ e de largura entre 6 a $12 \mathrm{~cm}$. O sistema radicular de um cajueiro adulto é caracterizado por uma raiz pivotante, a qual pode atingir ate $10 \mathrm{~m}$ de profundidade conforme as condiçes edáficas. Possui ainda um verdadeiro emaranhado lateral de raizes que representa para a planta uma grande importancia (BARROS \& MELO, 1987).

ARGLES (1976) cita que a planta durante o ano passa por duas a três fases de crescimento, sendo normalmente um fluxo vegetativo e outro generativo, sendo que este último termina numa inflorescência. A planta apresenta ainda dois tipos de ramificaçoes, sendo uma extensiva e outra intensiva. A intensiva cresce de 25 a $30 \mathrm{~cm}$ e termina numa panicula, que dá origem de três a oito novos ramos, que crescem de $10-15 \mathrm{~cm}$ além do ápice e também podem originar inflorescências. Por outro lado a ramificaça extensiva cresce 20 a $30 \mathrm{~cm} e$ normalmente desta nao se origina inflorescência, apesar de que de 5 - $8 \mathrm{~cm}$ do seu ápice, surge novo ramo do mesmo tipo. Portanto, a ramificaça extensiva é responsável pelo formato aberto e esparramado da copa, enquanto a intensiva responde pelo formato caracteristico desta.

o cajueiro e uma planta andromonoica, com inflorescencia do tipo panicula terminal, contendo flores masculinas (estaminadas) e hermafroditas numa mesma panicula, sendo que cada ramo da panicula origina uma flor terminal, a 
qual é seguida por duas bracteas, que através de suas axilas originam novas flores. As flores sao poligamas de dois tipos: perfeitas e estaminadas. Segundo COPELAND (1961) de uma maneira geral, a flor terminal de cada ramo é perfeita e as laterais sao estaminadas.

A flor do cajueiro é formada por cinco sépalas, cinco petalas e contém de seis a dez estames. A flor masculina possui de seis a dez estames, sendo um deles protuso, que produz uma antera vermelha que se projeta para o exterior da corola, e os demais sao pequenos e permanecem no interior desta. Na flor bissexual ou hermafrodita, o cálice, a corola e o androceu sqo similares aqueles das flores estaminadas, diferindo porém quanto ao gineceu que é uma estrutura desenvolvida, apresentando um ovário súpero, monocarpelar. o estilo é grosso tornando-se conico ao final, com estigma ligeiramente achatado. No entanto na flor estaminada, o gineceu é uma estrutura rudimentar e sem funça (NAIR, 1980).

a numero total de flores por panicula varia de 200 a 1.600, porém, a relaçao entre flores péffeitas ou hermafroditas com flores estaminadas varia entre plantas de diferentes regides, entre plantas de um mesmo local e até mesmo entre panicula de uma mesma planta. Segundo RAO \& HASSAN, 1957 e FALUYI, 1983, a variaça chega de 0,5\% ate um percentual superior a $33 \%$ de flores hermafroditas numa mesma panicula. 
De uma maneira geral o periodo de florescimento tem duraça que varia de cinco a sete meses, sendo que a epoca depende do periodo e da distribuicao pluviometrica. No Brasil, particularmente na regiăo litorânea do estado do Ceará, em anos de invernos normais o florescimento extende-se de julho a dezembro, ocorrendo a pico de produçåo entre a sequnda quinzena de outubro e meados de novembro (BARRQS, 1988a). Por outro lado, o cajueiro do tipo ană precoce, apresenta um periodo de florescimento mais dilatado em relaçăo ao do tipo comum, muito embora neste Último seja possivel encontrar plantas que florescem o ano inteiro e outras que apresentam um periodo concentrado de floraçăo (BARROS, 1988a).

A castanha, o fruto verdadeiro do cajueiro, é um aquentio riniforme que se liga a planta por meio de um pedúnculo hipertrofiado, que muitas vezes erroneamente e chamado de fruto. O fruto verdadeiro é constituido de três partes: casca, pelicula e a amêndoa, sendo a última parte a mais representativa em termos económicos, seguida da casca que contém um liquido presente em seu mesocarpo, 'ruma camada de células esponjosas que representa também produto de alto valor, na exportaçăo. Já o pseudofruto é consumido "in natura", na forma de suco, de doces diversos, cajuina, geléia, mel, vinho e aguardente, sendo a forma de suco a mais representativa em termos econâmicos, em relaçă ao mercado interno. 


\subsection{Cajueiro do tipo comum}

- cajueiro do tipo comum é uma planta que se caracteriza por seu porte alto, cuja altura media é de 5-6 m, podendo atingir 10-12 metros e a diametro da copa $15-20 \mathrm{~m}$. Apresenta uma grande variaçăo na distribuiço dos ramos e formato da copa, podendo esse ser de ereto e compacto, até esparramado. As plantas iniciam o florescimento normalmente no terceiro ano, com duraçăo anual media de 5 meses, podendo atingir 7 meses, o que é em funçăo do regime pluviometrico durante a estaçă chuvosa. As flores estao arranjadas em inflorescências do tipo panicula terminal, sendo o comprimento, o número de ramificaçøes e duraçăo desta, maior neste tipo de planta, quando comparado com o cajueiro do tipo ango precoce (PINHEIRo \& PARENTE, 1977). A capacidade produtiva individual do cajueiro do tipo comum é bastante variável, chegando a produzir uma media anual de castantia por planta entre 2 e $6 \mathrm{~kg}$, embora hajam informaçoes de ate 280 kg/planta. A castanha e o pseudofruto também apresentam variaçøes em seus pesos individuais, a primeira de 3 a 309 , enquanto a sequndo de menos 209 a mais de $500 \mathrm{~g}$. 


\subsection{Cajueiro do tipo anäo-precoce}

Caracteriza-se por um porte mais baixo, copa compacta e homogênea, folhas menores do que o cajueiro comum e de um verde menos intenso, com a primeira ramificaçăo situando-se mais próxima ao solo. As plantas apresentam altura média variando de 2,5 a $4,5 \mathrm{~m}$, dependendo do sistema de propagaçăo adotado, com envergadura năo atingindo a valores superiores a $9,0 \mathrm{~m}$. O florescimento inicia-se no segundo ano, embora algumas plantas possa florescer já no primeiro ano. A duraçăo é no minimo de dois meses a mais do que no cajueiro do tipo comum, com um intervalo de junho a janeiro, tendo um pico de florescimento no mês de agosto, embora possam ocorrer plantas que em funçăo do regime pluviometrico, floresçam o ano inteiro. Como no cajueiro do tipo comum, a frutificaçao ocorre no periodo seco, sendo a sua duraçao mais alongada com colneitas até fevereiro, enquanto no cajueiro comum a colheita encerra-se normalmente em janeiro. A capacidade produtiva individual é menor do que no cajueiro comum, havendo registros máximos de cerca de 43 kg de castantialano. 0 peso do pseudofruto apresenta uma variaçă menor, atingindo valores superiores aos registrados no tipo comum, sendo que o máximo valor atingido nåo excede a 2009 (BARROS, 1991 ). 


\subsection{Alguns aspectos da biologia floral do cajueiro}

o conhecimento da biologia floral do cajueiro é de relevante importância tanto do ponto de vista botânico quanto com relạ̧o ao melhoramento genético, e também, como nao poderia deixar de ser, de suma importancia no estudo da polinizaçao da cuiltura. Com relaçă ao primeiro caso, a conhecimento das caracteristicas morfológicas das flores, contribui de modo relevante na determinaça das especies conhecidas de Anacardium e com o passar do tempo, quiçá poderá contribuir ainda mais para a conhecimento de novas especies, variedades botânicas e ecotipos. No segundo caso, a importancia é do ponto de vista do melhoramento genético da cultura e também no que concerne ao estudo da polinizaça entomofila da cultura. Especificamente, com relaçao a polinização realizada pelos insetos, o contecimento do hábito de florescimento, a epoca da formaça do fruto, os processos de abertura das flores, polinizaça, indice de sexualidade e fixaçao dos frutos saro informaçaes imprescindiveis quando se trabalha com polinizaça.

\subsubsection{A inflorescência e flores}

o cajueiro é uma planta que apresenta flores bissexuais ou hermafroditas e masculinas numa mesma panicula, sendo portanto, uma planta andromonóica. A inflorescência é 
uma panicula terminal composta pelos dois tipos de flores em quantidades e proporçeses que variam bastante entre plantas, de regiao para regiå, e até mesmo dentro de uma mesma panicula. Cada panicula contem entre 5 a 11 ramos laterais e - total do número de flores por inflorescencia varia de 21 a 881 com uma media de 316 , e o número de flores hermafroditas varia de 1 para 82 com uma media de 13 (RAO \& HASSAN, 1957 ). Porem, outros estudos mostram um número de cerca de 60 flores hermafroditas por panicula e uma proporcago de $6: 1$ de flores masculinas para flores perfeitas (NORTHWOOD, 1966). De uma maneira geral, a flor terminal de cada ramo na panicula é perfeita enquanto que as laterais sao estaminadas (COPELAND, 1961). Algumas observaçoes dão conta de que apenas $10 \%$ das flores perfeitas produzem frutos, cóm uma media em torno de 5 frutos por panicula (NORTHWOOD, 1966).

Os dais tipos de flares possuem essencialmente a mesma estrutura, ou seja, ambas possuem ovário, estilo e estigma, sendo que na flor masculina o gineceu ná é funcional, sendo representado por uma estrutura rudimentar (COPERLAND, 1961 ).

Uma flor perfeita contém 5 sépalas, 5 petalas (pentamera), 6 a 10 estames (sendo um grande e funcional e 5 a 9 pequenos e parcialmente estereis) e um ovario simples (rudimentar nas flores masculinas). Nas flores hermafroditas este é totalmente desenvalvido possuindo um estilo, o qual suporta em sua extremidade o estigma ficando este sempre em 
plano superior as anteras, o que de certo modo, pode justificar a açă dos agentes polinizadores. Por outro lado, os graos de polen saro pegajosos, o que provavelmente descarta a possibilidade da polinizaçăo anemófila como sendo mais importante (MEDINA, 1978 e BARROS, 1988a).

Como o presente trabalho é dirigido apenas para o cajueiro do tipo anå-precoce, é interessante conhecer as diferenças entre os caracteres das paniculas do tipo em estudo com as paniculas do cajueiro comum. Deste modo, PINHEIRO \& PARENTE (1977), realizando um estudo preliminar da biologia floral dos dois tipos, verificaram que: a) 0 comprimento, a número de ramificaçôs e a duraçăo da panicula do cajueiro anao-precoce sao menores que no tipo comum; b) em ambos os tipos ocorre a predominancia das flores estaminadas em relaça às hermafroditas; c) o tipo precoce apresenta um número total de flores por panicula superior ao comum, entretanto, menor quantidade de flores hermafroditas; d) a relaçăo entre o número de flores masculinas e hermafroditas (indice $I_{2}$ ) e maior no tipo precoce que a relaçao entre o número de flores hermafroditas e o número total de flores $(I=)$ e mais elevada, e o número total de frutos que alcançaram o pleno desenvolvimento é muito baixo em ambos os tipos, sendo levemente superior no tipo anao-precoce. 
2.7.2. Epoca de florescimento

A epoca de florescimento em cajueiro é muito variável, com variaçao de 5 a 7 meses, a qual está relacionada com o periodo de distribuiçao das precipitaçoses variando também de regiăo para regian.

No Brasil, notadamente na regiă litoranea do estado do Ceará, em anos considerados de periodo chuvoso normal, vai de julho a dezembro, o que acarreta um pico de produçăo concentrado entre a segunda quinzena de outubro e o final de novembro. No entanto, $85 \%$ da produçăo concentra-se de outubro a dezembro. Por outro lado, observa-se que a variaço no periodo de florescimento da cultura é muito grande, sendo no entanto possivel observar plantas que florescem o ano inteiro e plantas com um periodo concentrado de florescimento. Segundo BARROS (1988a), o periodo de florescimento do cajueiro do tipo ango-precoce é mais alongado em comparaçăo com o do tipo comum.

A variaça na época de florescimento dessa frutifera ocorre em periodos diferentes, de ácọdo com a regiao que ela é cultivada. Na Tanzânia a epoca de florescimento ocorre de julho a dezembro, com um pico em agostosetembro (NORTHWOOD, 1966) coincidindo assim com a época de florescimento no Brasil. Porém, na India ocorre de maneira diferente, a época de florescimento estende-se por cerca de 7 meses (de setembro a março), com ocorrência de pico de 
dezembro a fevereiro, com um tempo requerido de 30 dias do rompimento do botao (antese) para o surgimento da primeira flor (NAIR, 1980).

\title{
2.7.3. Antese
}

\begin{abstract}
A aritese ou abertura das flores do cajueiro segue um certo modelo, no qual em primeiro lugar, há uma fase de abertura de flores masculinas, seguido por outra na qual acontece uma fase mista em que flores masculinas e nermafroditas abrem-se e uma terceira e última fase, ande somente flores masculinas abrem-se
\end{abstract}

0 conhecimento do periodo de abertura das flores, no caso particular do caju, tem uma capital importancia para realizar-se um trabalho de polinizaça dirigida e ate mesmo quando se pensa na preservaçăo dos agentes polinizadores durante a aplicaçă de defensivos agricolas visando o controle de pragas. As flores masculinas iniciam a antese por volta das b he se prolonga por todo a dia aproximadamente até $16 \mathrm{~h}$. Ja a abertura das flores hermafroditas concentra-se entre 10 e $12 \mathrm{~h}$, havendo pouca variaçăo (RAO \& HASSAN, 1957 E NAIR, 19801.

PARAMESWARAN et al. (1983) estudando a relạ̧o entre a duraçă da fase masculina e mista, respectivamente, verificaram que as plantas com 4,6,74 e 5,1 dias de duraçao para cada fase apresentaram produçao superior à média num 
lote de 20 seleçoes. Já as plantas que tiveram respectivamente $13,4,75,9$ e 13,4 dias para as três fases apresentaram produça abaixo da média. Afirmam ainda os autores, que todas as plantas com produçăo superior à média tiveram uma proporçao das fases masculinas sobre o total, significativamente mais baixa, a que os levou a concluir que isso pode ter influenciado a formaçao de frutos devido uma maior chance de polinizaçăo.

\subsubsection{Deiscência da antera e receptividade do estigma}

o contecimento dos periodos de deiscencia das anteras e da receptividade do estigma das flores das plantas beneficiadas pela açă dos agentes polinizadores é de fundamental importancia para uma polinizaçao satisfatória no campo. Porém, no Brasil, nå se dispoe de estudos pertinentes a essa parte da biologia floral. Na india foram realizados estudos onde RAO \& HASSAN (1957) citam que o estigma encontra-se receptivo ao longo do dia, perdendo tal receptividade ao final deste, e que a antera inicia a deiscência a partir das 10 h30 mudando da cor cinza para a rosa no final do processo. Já, nos estudos realizados por DAMODARAN et al. (1966) o estigma está receptivo um dia antes da antera e assim permanece até dois dias apos esta, sendo que o melhor periodo em termos de florescimento para a polinizaçăo cruzada 
é até o meio-dia do dia da abertura da antera. Ainda, de acordo com esses autores, foi verificado que a deiscecia da antera ocorre quase que totalmente entre in e $11 \mathrm{~h} 30$, apresentando uma maior intensidade até as 10 h3o nos lados da planta em que a intensidade dos raios solares é maior. Para NAIR (1980) a deiscencia da antera apresenta um periodo de pico entre $9 h$ e $11 \mathrm{~h} 30$, por outro lado, o estigma da flor é receptivo um dia antes da antera, sendo o periodo ditimo de receptividade ao meio dia do dia da antese.

$$
\text { Pelo exposto anteriormente, verifica-se que }
$$

existe uma sincronia entre o processo de deiscencia das anteras das flores e receptividade dos estigmas, o que reforça a assertiva de que a polinizaça entomófila no cajueiro faz-se necessária, muito embora haja uma perfeita sincronia entre as processos acima citados. Deve-se tambem analisar a fato levando-se em consideraça a posiça do estigma, que fica em plano superior em relaçă as anteras e por outro lado a pegajosidade dos graos de pólen que inviabiliza em parte, a polinizaçao anemofila e enaltece a entomófila. 


\subsection{Importância da polinizaçăo entomófila para o cajueiro}

A polinizaçao consiste na transferencia dos graos de pólen das anteras (parte masculina) para o estigma (parte feminina) das flores. Quando essa transferência ocorre da antera de uma flor, para o estigma da mesma ou de uma flor da mesma planta, denominamos autopolinização ou polinizaça direta ou ainda autogamia. No entanta, quando a transferência de polen acontece da antera de uma flor para estigma de outra flor da mesma espécie, porém, em pés diferentes, caracterizase a polinizaçăo cruzada que também pode ser chamada de alogamia. A polinizaçăo do ponto de vista agricola tem sua importancia galgada nos insetos polinizadores, sendo estes importantes na produça de frutos e sementes, cuja quantidade depende do número de óvulas fecundados e a qualidade depende, para algumas especies, da hibridaça entre variedades. Entre os insetos destacam-se as abelhas e entre essas, as do gênero Apis como sendo as que mais contribuem para uma'polinizaça mais efetiva nas lavouras. Isso ocorre em conseqüencia dos polinizadores nativos estarem escasseando devido ao aumento das áreas de monoculturas cultivadas, o que vem causando a destruiça de seus ninhos e tambem a uso de praticas agricolas que muitas vezes tem efeito destruidor sobre esses. De acordo com a artigo "IMPQRTANCIA da polinizaçăo (1986)", 
na França, as abelnas sao consideradas essenciais a polinizaçă, especialmente a de plantas cultivadas de grande expressao econamica, garantindo-se que a participaçă da abeliha na agricultura como agente polinizador, representa um valor de 12 a 15 vezes superior a valor comercial de todos os produtos oriundos, da colmeia. Segundo CRANE (1983), nos trópicos, algumas plantas sao polinizadas pelos pássaros, no entanto, em qualquer local sao polinizadas por insetos, e dentre esses, as abelhas sao as mais eficientes pela sua constancia, fidelidade ou lealdade a coleta, devido ao grande número de polinizadores potenciais e pela grande facilidade no transporte das colméias de uma cultura para outra na época do florescimento. A evidencia da importancia das abelhas (Apis) no processo de polinizaçă das culturas torna-se ainda mais relevante, quando consideramos que uma colonia pode realizar cerca de 4 milheres de viagens durante um ano e que por ocasiáo de cada uma destas viagens, uma média de 100 flores sao visitadas (FREE, 1970a).

No inicio do seculo, foi estimado que o número de colmeias adequadas, em determinada área para 'polinizaçă era de 2 e 2 'ć colméias por hectare. Já para freE (1970a), o número de colméias por hectare é determinado em funça da presença de insetos, de autras culturas concorrentes da atratividade das flores $e$ da quantidade de flores disponiveis. Tais parâmetros sao sujeitos a variaçøes de um lugar para outro e de ano para ano. Levando-se em 
consideraçă o número de colméias, MCGREGOR (1976a) diz que um numero considerado razóavel é a de uma a duas abelhas por 100 flores, naro obstante, quando a cultura nå é considerada muito atrativa ou quando existe a concorrencia de outras culturas e insetos, este número deve ser aumentado. 0 inverso é verdadeiro quando a cultura é atrativa ou pode ser autopolinizada.

A polinizaçăo cruzada apresenta mais vantagem, devido a possibilidade de novas combinaçoes geneticas, o que favorece a formaça de sementes, originando novas plantas com maior vigor e maior produtividade. Na natureza as plantas exibem vários mecanismos de defesa para evitar a autopolinizaçăo, dentre os quais os agentes polinizadores, tais como os animais, a água e os insetos, sendo estes, as mais importantes. Dentre os insetos destacam-se as abelhas, que ao longo da evoluçao desenvolveram mecanismos apropriados para se tornarem os mais eficiente polinizadores: como a presença de pelos em todo a corpo, que favorece o transporte dos graos de pólen $e$ a sofisticaçăo do sistema de comunicaçao, que permite uma abeliha campeira ' localizar e indicar rapidamente uma florada para suas companheiras (MART INHO, 1989).

Dentre as culturas beneficiadas pela polinizaçăo das abelhas, as frutiferas representam uma grande parcela, as quais aparecem freqüentemente citadas nas listas das plantas apicolas beneficiadas para produça economica de 
frutos e sementes. Entre as frutiferas citadas como beneficiadas pela polinizaçăo das abelhas encontramos o cajueiro (KERR \& AMARAL, 1960; GIORGINI \& GUSMAN, 1972; FREE \& WILLIAMS, 1976 e MEDINA, 1978).

Existe entre as autores que estudaram a polinizaçăo em cajueiro, muitas controversias em relaçăo ao agente mais importante na polinizaçao dessa Anarcadiacea. Alguns afirmam ser o vento, existem também aqueles que asseguram ser os insetos e ainda existem aqueles que afirmam serem ambos, como tambem existem aqueles que asseguram ser a polinizaçăo exclusivamente entomófila, a mais importante na transferência do pólen. Nă obstante, de acordo com a estrutura das partes reprodutivas da flor (estame e estigma) os quais estro localizados em planos distintos e a natureza pegajosa dos grăos de pulen, o que dificulta a açăo do vento e da gravidade no transporte desses para o estigma, há de se convir, que os insetos na realidade apresentam maiores possibilidades na execuçă deste processo. Por outro lado, possivelmente uma parte ponderável do polen das plantas visitadas pelos insetos, quando transportado pelq vento ou pela gravidade, foi antes desprendido das anteras das flores devido a açăo dos insetos (NOGUEIRA NETO, 1953). Desta maneira, a açăo desses agentes polinizadores, caso a assertiva citada anteriormente seja verdadeira, nao deve ser descartada do processo de polinizaça das flores do cajueiro, muito embora na natureza o processo de polinizaço das 
plantas que dela depende far-se-a mais efetivamente com a presença de polinizadores.

\subsubsection{Polinizaça em cultura de cajueiro}

ser devida a ausência de uma polinizaçao natural adequada, sendo essa demonstrada eficientemente atraves da excepcional fixaçă (55\%) de frutos sob condiçdes artificiais. O papel dos insetos no processo de polinizaçăo parece ser insignificante, e entre os agentes naturais, bioticos e abioticos, o vento foi o único que auxiliou a polinizaça, muito embora a fixaçá de frutos possa ser aumentada em condiçes nas quais a frutifera seja consorciada com outras plantas com maior espaço para a atividade dos insetos (RAO \& HASSAN, 1957).

KERR \& AMARAL (1960), citam o cajueiro na lista das principais plantas que se beneficiam com a presença das abelhas para produça de frutos e sementes. Esses autores tambem afirmam que em certos lugares da Tanzânia! os negros selvagens roubavam colânias de abelhas para colocálas nos cajueiros com o objetivo de aumentar a produçao de frutos. SMITH (1960) fazendo referência a importância das plantas no que se refere ao seu. valor forrageiro para as abelhas, cita o cajueiro como uma planta de alto valor na lista das plantas beneficiadas pela polinizaça dos insetos. 
Além do cajueiro a referido autor também cita a coqueiro (Cocas nucifera), sisal (Agave sibana) e o cafeeiro (Coffea arabica) nesta mesma categoria.

BINGGER (1960) afirma que sendo a cajueiro uma planta que possui uma alta percentagem de flores masculinas, sugere o vento como um agente polinizador, o que na verdade contraria a colocaçáo de outros autores, pelo fato do pólen do cajueiro ser pegajoso.

De acordo com DAMDDARAN et al. (1966) a estrutura da flor do cajueiro apresenta maior tendencia para a polinizaça cruzada do que para autopolinizaçăo. Na flor hermafrodita, o estame desenvalvido écerca da metade do comprimento do estilo e sua antera geralmente abre-se somente tarde da noite, sendo por essa razao a chance do estigma ser polinizado pelo polen de alguma flor, muito rara. Segundo ainda os autores, o presente estudo nao indica nentum grau de incompatibilidade de autopolinizaça ou polinizaça cruzada e a estrutura da flor favoreceria a polinizaça cruzada, e o vento pareceu ser o principal agente polinizante. Ainda de acordo com os autores, os estamináides em condiçáę naturais năo apresentaram nenhum papel significativo na polinizaçă, muito embora eles apresentem alguns graos de polen viáveis.

NORTHWOOD (1966) estudando a polinizaçăo em cajueiro, verificou que a polinizaçao realizada pelos insetos' (entomófila) é mais importante do que aquela feita pelo vento (anemófila). Segundo ainda o autor, o forte aroma 
das flores, a viscosidade do polen e a diferença existente entre o tamanho do pistilo (mais comprido) e os estames, reforga a ponto de vista de que as insetas såo agentes polinizantes mais eficazes do que o vento.

Segundo PURSEGLOVE (1968), as flores do cajueiro săo visitadas por moscas, formigas e outros insetos, sendo esses capazes de fazerem a transferencia do pólen pegajoso para o estigma da flor. Cita ainda, que no Sul da Tanzânia, a produçao de flor, polinizaça e fixaça de frutos sao eficientes e normalmente nă limitam o rendimento. Nă obstante na India a polinizaça năo foi tida como eficiente e - incremento na fixaçăo de frutos foi obtido por polinizaçao artificial.

FREE (1970a) afirmou que embora poucos experimentos tentiam sido realizados para elucidar o problema da polinizaçăo em cajueiro, há indicặo de que a autopolinizaçăo é tăo efetiva quanto a polinizaça cruzada, năo obstante, flores isoladas nao produzirem frutos, a nao ser quando polinizadas artificialmente, concluindo o autor que algum agente é necessário para transferir o polen.'.'

\section{GIORGINI \& GUSMAN (1972) estudando a} importância das abelhas na polinizaçao, cita em sua lista de plantas apicolas com produça econômica, a cajueiro como sendo uma planta beneficiada para produçao de fruto, muito embora as informaçoes colnidas pelo referido autor tenham sido oriundas de declaraçôs pessoais. 
Smith², citado por JOHNSON (1974), sugere que as abelhas podem ser usadas para incrementar a polinizaçao do cajueiro. Referindo-se ainda ao cajueiro, a autor enfatiza que a ocorrência de um acentuado aroma das flores, os grăos de pólen pegajosos, reforçam a assertiva da importância dos insetos como agentes polinizadores da cultura.

Wulfrath \& Speck, citados por McGREGOR (1976b), afirmam que as flores do cajueiro permanecem atrativas para as abelhas durante todo o dia devido ao seu rico néctar.

FREE \& WILLIAMS (1976) estudando o efeito da polinizaçăo entomófila em quatro frutiferas, entre as quais a mangueira e o cajueiro (mesma familia) verificaram que a maior parte da polinizaça das flores do cajueiro foi feita por abelhas que realizaram suas visitas cedo, muito embora formigas e dipteros tenham contribuido. Os autores tambem fazem inferencia, que em locais onde existem pequenos insetos polinizadores, a introduça de familias de abelhas nas culturas poderiam aumentar a polinizaçao.

MCGREgOR (1976b) declarou que nao existe recomendaçăo quanto ao uso de insetos na polinizaçăo do caju, nao obstante, evidências fortes indiquem que, concentraçoes

1 SMITH, F.G. "Breekeeping operations in Tanganyica 19491957". Bee World, Benson, 39: 29-6, 1958.

× WULFRATH. A. \& SPECK, J.J. La flora mellifera. 2.ed. México, EdiçOes Mexicanas, s.d. 96p. (Enciclopedia Apicala, 28). 
de colonias de abelhas em cajueiros durante o florescimento poderiam amenizar o problema da baixa fixaça de frutos e cita também que a seleçăo de clones com alta percentagem de flores hermafroditas poderia sem dúvida aumentar a produçå.

$$
\text { MEDINA (1978) afirma que o florescimento é }
$$

bastante elevado no cajueiro e que o número de flores por panicula pode variar de 200 a 1.600 . As inflorescências sao constituidas por paniculas terminais, compostas de ramos, que comumente produzem flores masculinas e hermafroditas, sendo que as primeiras saa as mais numerosas. O autor cita também que as flores hermafroditas apresentam sempre o estigma em plano superior ás anteras e que dificilmente a autofecundaço pode ser realizada. Segundo ainda o autor, o cajueiro apresenta os graos de pólen viscosos, dificultando a polinizaçao anemófila, chegando a conclusao final de que a falta de polinizaçao cruzada no cajueiro pode ser considerada como um motivo de baixa producaro em determinadas condiçoes, sendo os insetos considerados as mais eficazes agentes polinizadores.

NAIR (1979) relata que a polinizaça em cajueiro é conduzida por moscas e formigas, assim tambem pelo vento.

NAIR (1980) afirma que de acordo com a estrutura da flor do caju, nas flores perfeitas ou bissexuais - estame desenvalvido (fértil) e apenas a metade do comprimento do estilo, ou seja, o estigma está localizado num 
plano superior en relaçao as anteras e a flor tem uma tendencia maior a polinizaçăo cruzada. o autor cita tambem que a auto-incompatibilidade em cajueiro não e noticiada e que a polinizaçao anemófila e predominante.

BARROS et a 1 . (1984) estudando o comportamento de progênies oriundas de cruzamentos livres, detectaram uma grande variabilidade entre a produçao das plantas, o que permitiu aos autores concluirem que o cajueiro é de polinizạ̧o cruzada.

REDDI (1987) estudando a polinizaça em cajueiro, atraves da comparaça do desenvolvimento de frutos em 750 flores, pertencentes a árvores de diferentes populaçdes na fndia, verificou que dessas $10,5 \% e 17,5 \%$ desenvolveram frutos, quando polinizadas naturalmente e atraves da polinizaço artificial respectivamente. o autor declarou ainda, que e possivel un aumento de $157,8 \%$ no desenvolvimento de frutos, caso as flores recebam polen adequadamente.

Segundo BARROS (1988a) o florescimento do cajueiro varia de 5 a 7 meses e a sua época é em funça da distribuicão pluviometrica. No 1 itoral cearense, em anos de precipitaçoes normais, vai de julho a dezembro, sendo que 85\% da produça concentra-se de outubro a dezembro. Observou-se tambem que existe uma variaçao bastante grande no florescimento, desde plantas que florescem o ano inteiro ate aquelas que apresentam o periodo de floraço mais 
concentrado. Já no cajueiro anáo precoce o periodo de florescimento é mais alongado do que no comum. Com a objetivo de estudar o fluxo de crescimento vegetativo e o desenvolvimento da floraçao, foram marcados até 18 ramos por arvore $e$ apos o inicio da floraça foram contados semanalmente em cada inflorescência o número de flores masculinas, hermafroditas e de frutos. Foi verificado a inexistência de fases com fluxo de flores masculinas e hermafroditas, como descrito na literatura para o cajueiro comum. Foi observado tambem, que nos cajuais de Pacajus (Ceará), alem das abelhas (Apis 5p.) visitaram as flores, outros himenópteros, vários dipteros e lepidópteras. Do total de 12 inflorescência isoladas com sacos de filo no clone CCP1001, apenas uma deu fruto, já outras 4 arvores de origem de policruzamento deram 11 frutas, porém nentuma desenvolveu-se. A equipe de pesquisadores conclui preliminarmente que a autopolinizaçă natural em paniculas isoladas acontece com mais frequência nas árvores provenientes de policruzamento, mas mesmo assim, nao se obtiveram frutos desenvolvidos (EMBRAPA, 1990 ).

BISPO \& COSTA (1991) estudando a ecologia dos insetos polinizadores potenciais do cajueiro na regiao nordeste da Bahia, realizaram uma coleta dos insetos que visitaram as inflorescencias dessa frutifera, a cada duas horas a partir das 6 horas da mantia até as 18 horas. De acordo com os resultados iniciais obtidos, a maioria dos 
exemplares capturados nas inflorescências no periodo observado pertenciam a ordem Hymenoptera (85,02\%), ficando (14,98\%) distribuidos entre as ordens Coleoptera, Lepidoptera e Diptera. Os autores ainda afirmam que possivelmente a ausência de agentes polizadores pode ser um dos fatores responsáveis pela baixa produtividade do cajueiro. 
3. MATERIAL E METODOOS

\begin{abstract}
a presente trabalho foi desenvolvido em área pertencente ao Centro Nacional de Pesquisa do Caju - CNPCa da EMBRAPA, onde foram obtidas dados pertinentes a polinizaça entomóila em cultura de cajueiro do tipo anao-precoce.
\end{abstract}

3.1. Localizaçăo do Campo Experimental de Pacajus (CEP)

o CEP pertence ao Centro Nacional de Pesquisa do Caju - CNPCa da EMBRAPA e está localizado na Microregiao Litoral de Pacajus, municipio de Pacajus, Estado do Ceará, com as coordenadas geograficas $4010^{\circ} \mathrm{s}$ e $38^{\circ} 27^{\circ} \mathrm{W}$ e a $60 \mathrm{~m}$ de altitude (EMBRAPA, 1990).

\title{
3.2. Caracterizaçăo da área experimental
}

\subsubsection{Clima}

- clima do CEP está enquadrado no tipo climático seco/úmido, segundo a classificaçăo climática de 
THORNTHWAITE (1948) com indices efetivos de umidade (Im) variando de -33 a 0 (zero). A precipitaça media anual é de $1100 \mathrm{~mm}$ com regime pluvial caracterizado por chuvas de verao/outono, apresentando duas estaçoes definidas: uma chuvosa na qual 90\% das precipitaçđes ocorrem no periodo de janeiro a jultio ę outra seca, correspondendo aos meses de agosto a dezembro, coincidindo com a epoca de frutificaça do cajueiro. A Tabela 1 apresenta os parâmetros climáticos médio referentes ao Campo Experimental de Pacajus, CE (EMBRAPA, 1990).

\subsubsection{So 10}

A área do CEP apresenta a seguinte classificaçao pedogenetica: Podzólico Vermelho - Amarelo Tb eutrofico A fraco, textura arenosalmedia (PE), Podzolico vermelno amarelo Tb distrofico A fraco, textura arenosa/media (PV) e Areia Quartzosa distrofica A fraco (AQd). As três unidades apresentam relevo plano e suave ondulado com declividade entre $0 \%$ e $6 \%$. As caracteristicas fisicas de maior importancia sao associadas a textura, e nos três solos estas caracteristicas estao marcadamente influenciadas pela condiça arenosa dos perfis. A Tabela 2 apresenta as caracteristicas fisicas e quimicas dos solos e os valores medios nos horizontes superficiais (Ap) e subsuperficiais (B 2T ou C) (EMBRAPA, 1990). 
Tabela 1. Parâmetros climáticos medios do Campo Experimental de Pacajus, CE (EMBRAPA, 1990).

\begin{tabular}{|c|c|c|c|c|c|c|c|c|c|c|c|c|c|}
\hline Partinetos & Jan & Fev & Mar & Abr & Malo & Jun & Jul & Ago & Set & Out & Nov & Dez & Medla \\
\hline Precloluapos (mm) & 100 & 151 & 277 & 239 & 143 & 84 & 39 & 13 & 11 & 15 & 09 & 25 & 1.108 \\
\hline Unid, relattva (\%) & 74 & 77 & 79 & 80 & 82 & 81 & 81 & 75 & 75 & 74 & 73 & 72 & 77 \\
\hline Temp. max, $\left({ }^{\circ} \mathrm{C}\right)$ & 32,0 & 31,8 & 31,0 & 31,2 & 31,0 & 30,9 & 31,4 & 31,8 & 32,2 & 32,4 & 32,6 & 32,8 & 31,8 \\
\hline Terme, mh $\left.\rho^{\circ} \mathrm{C}\right)$ & 20,4 & 20,5 & 20,7 & 20,5 & 20,4 & 19,4 & 18,4 & 18,4 & 18,9 & 19,0 & 19,0 & 19,0 & 19,6 \\
\hline Temp med, $\left({ }^{\circ} \mathrm{C}\right)$ & 28,2 & 26,2 & 25,9 & 25,9 & 25,7 & 25,2 & 24,9 & 25,1 & 25,6 & 25,7 & 25,8 & 26,2 & - \\
\hline Vel vento (m/s) & 4,0 & 3,3 & 2,8 & 2,6 & 3,0 & 3,4 & 3,9 & 4,8 & 5,5 & 5,1 & 4,8 & 4,5 & 4,0 \\
\hline
\end{tabular}

Tabela 2. Caracteristicas fisicas e quimicas dos solos; valores médios nos horizontes superficiais (Ap) e subsuperficiais (B2T ou C) (EMBRAPA, 1990).

\begin{tabular}{|c|c|c|c|c|c|c|c|c|c|c|c|c|}
\hline \multirow{3}{*}{ Solo } & \multirow{3}{*}{$\begin{array}{l}\text { Parte do } \\
\text { pertill' }\end{array}$} & \multicolumn{8}{|c|}{ Caractertsticas ${ }^{2}$} & \multirow{3}{*}{$\frac{\begin{array}{c}\text { Troct- } \\
\text { vois }\end{array}}{\mathrm{Na}}$} & \multirow{2}{*}{\multicolumn{2}{|c|}{$\begin{array}{c}(\mathrm{meq} / 100 \mathrm{~g} \\
\text { de soto) }\end{array}$}} \\
\hline & & & Texture & & & MO & $\mathbf{P}$ & Câth & & & & \\
\hline & & AR & St & Arg. & $\mathrm{pH}$ & & & $\mathrm{Ca}+\mathrm{Mg}$ & $\mathbf{K}$ & & H & A \\
\hline \multirow{2}{*}{ PV } & SUP & 91,5 & 3,0 & 5,5 & 5,4 & 0,95 & 2 & 1,00 & 0,07 & 0,04 & 1,7 & 0,10 \\
\hline & SUB & 61,5 & 9,0 & 29,5 & 4,9 & 0,65 & 1 & 0,65 & 0,08 & 0,06 & 1,4 & 0,60 \\
\hline \multirow{2}{*}{ PE } & SUP & 91,0 & 4,0 & 5,0 & 5,3 & 0,80 & 3 & 0,90 & 0,14 & 0,11 & 0,6 & 0,10 \\
\hline & SUB & 68,0 & 15,0 & 17,0 & 4,8 & 0,40 & 2 & 0,70 & 0,11 & a;11. & 0,2 & 0.70 \\
\hline \multirow{2}{*}{ AOd } & SUP & 95,0 & 1,0 & 4,0 & 5,5 & 0,50 & 1 & 0,80 & 0,05 & 0,05 & 0,8 & 0,10 \\
\hline & SUB & 89,0 & 2,0 & 9,0 & 4,9 & 0,16 & 1 & 0,40 & 0,04 & 0,06 & 0,8 & 0,20 \\
\hline
\end{tabular}

1 SUP = Solo superficial (AP); SUB = Solo subsupericlal (BZt ou C).

2 AR = Areia; SI = Sille; ARG = Argila: M.O. = Matéria Orgánica; $P=$ Fóstoro; Ca = Cálcio; Mg = Magnésio; $K=$ Potássio; Na = Sơdlo; $H=$ Hidrogó nio; $\mathrm{Al}=$ Alumínio. 


\subsection{Teste de polinizaçao en cultura de cajueiro}

Foram utilizadas duas áreas plantadas com dois clones de cajueiro anao-precoce, CCP - 76 e CCP - 06, de respectivamente 160 e 500 plantas com idade de 5 anos. Os referidos clones foram obtidos a partir das plantas CP - 76 e CP - O6 propagadas por sementes coletadas no municipio de Maranguape no Estado do Ceará no ano de 1956 (BARROS, 1988b). As duas áreas apresentavam espaçamentos diversos entre plantas, por se tratar de uma área experimental para determinaçăo de melhor espaçamento entre plantas.

Nas proximidades das áreas onde foi conduzido - presente trabalho havia um apiario com 60 colmeias modelo Langstroth compostas de um ninho e duas melgueiras, povoadas com colânias de abelhas (Apis mellifera L.) com uma distancia do apiário até as áreas dos cajueiros de aproximadamente 200 metros. Vale ainda salientar, que o pasto apicola das áreas circunvizintias encontravam-se em estado final do periodo de floraço, sendo portanto, a florada do cajueiro, na ocasiăo, praticamente a única fonte de nectar e polen disponivel para as abel has.

No periodo do experimento as duas áreas nă receberam tratos culturais a năo ser no periodo da colheita quando foi feita uma roçagem mecannica para facilitar a colheita dos frutos e pseudofrutos (pedúnculo), como também naa receberam qualquer tipo de adubaça, correça do solo nem tao pouco, aplicaço de produtos quimicos para controle de pragas e doenças.

No inicio do florescimento, julho a agosto de 1991, foram selecionadas ao acaso dez árvores dos clones CCP - 76 e 10 de CCP - 06, as quais ainda apresentavam em suas paniculas botoes florais. Posteriormente, 20 paniculas, com aproximadamente o mesmo comprimento em cada arvore dos dois clones, foram ensacadas com sacos de fild, sendo outras 20 mantidas etiquetadas, servindo como testemunta. Durante o 
periodo de florescimento foram feitas trés avaliaços do número de frutos fixados nas paniculas impedidas de visitaçao e também naquelas que estavam livres em ambos os clones.

As avaliaçes foram feitas nas datas: $28 / 08$. $18 / 09$ e 30/09/91 para o clone CCP - 06 e 27/08, 11/09 e $30 / 09 / 91$ para o clone CCP - 76. Essas avaliaçoes foram feitas através da contagem e marcaçăo do número de "maturis" (frutos recem vingadosl para evitar que estes fossem recontados. 0 fato de se ter realizado mais de uma avaliaça por árvore e por panicula é justificado pelo fato de que o cajueiro é uma frutifera que apresenta comumente em suas inflorescencias frutos em diferentes estágios de desenvolvimento, chegando mesmo ao ponto de numa mesma inflorescencia encontrar-se desde botoes florais até frutos totalmente desenvolvidos, o que caracteriza bem uma planta em seu semiestado de domesticaçơ (BARROS, 1988a).

o horário e número de visitas de insetos, foi feito através de contagem do número dessas, observaçoes feitas em seis paniculas, por quatro horarios: 6 - 8h30; 9 $11 \mathrm{~h} 30 ; 12$ - $14 \mathrm{~h} 30$ e 15 - 17h30. Para determinar a duracaro de visitas foi usado um cronografo digital marca TECHNos, modelo 219, para registrar a tempo de permanencia dos insetos por panicula dentro dos quatro periodos supra citados.

Para a determinaça do número, horário e duraçăo de visitas foram marcadas aleatoriamente 7 árvores do clone CCP - 06, nas quais foram etiquetadas seis paniculas com aproximadamente o mesmo comprimento e idade, localizadas a altura do terço médio das árvores. As observaçaes foram feitas a distancia (aproximadamente $5 \mathrm{~m}$ ), para que nao houvesse interferencia na aproximaça e visitas dos insetos.

Os insetos foram coletados através de rede entomologica, sendo mortos, montados, etiquetados e enviados a especialistas para identificaçao. Os de ordem Hymenoptera foram identificados pela Dra. Vera Ligia Letizio Machado (Departamento de Zoologia do Instituto de Biociências - UNESP 
- Rio Clarol e as demais pelos frofessores Dr. Sinval Silveira Neto e Dr. Roberto Antonio Zucchi (Departamento de Entomologia - ESALQ/USP).

Ds frutos fixados e desenvolvidos nas inflorescências protegidas e livres a visitaçăo dos insetos, amostras de 10 e 19 frutos de paniculas ensacadas dos clones CCP-76 e CCP-O6 respectivamente, foram pesados e obtido o peso médio. Do mésmo modo uma sub amostra de 30 frutos colnidas em paniculas nao ensacadas dos clones referidos anteriormente foram pesados para determinaçao do peso medio. As mesmas amostras citadas anteriormente foram enviadas ao Laboratório de Tecnologia de Gleos Vegetais do Departamento de Ciencias e Tecnologia Agroindustrial ESALQ/USP para realizaçao de análise de composiçăo centesimal. Os frutos foram quebrados para obtençao das amêndoas, as quais foram trituradas para determinaçăo do teor de oleo, proteina e cinzas na matéria seca.

\subsubsection{Teor de umidade}

Amostras de 1.09 foram pesadas em placas de vidro, levadas a estufa a $100 \circ \mathrm{C} \pm 20 \mathrm{C}$ por 12 horas, resfriadas em dessecador, pesadas e devolvidas a estufa de onde foram retiradas periodicamente até atingirem massa constante.

\subsubsection{Teor protélica bruto}

A determinaçăo do teor de nitrogênio total foi feito conforme a método de micro Kjeldahl, segundo a A.Q.A.C (1990) usando-se 0,059 de amostra. o fator de correço utilizado foi 6,25 para a obtença do teor de proteina bruta. 


\subsubsection{Cinzas}

Tomou-se uma amostra de $1,0 g$ e fez-se a
pesagem em cadinhos, os quais foram colocados em forno de
mufla para incineraço do material organico. Apos serem
retirados da mufla foram colocados em dessecador até
atingirem a temperatura ambiente para a pesagem, segundo PREGNOLATTO \& PASCUET, 1985.

\subsubsection{Teor de óleo}

Foi pesada 1,09 da amostra em cartucho de papel de filtro e feita a extraçao do bleo com hexano p.a. em extrator Butt segundo método da A.O.C.S., 1983.

\subsection{Análise estatistica}

0 delineamento experimental utilizado foi inteiramente casualizado, com esquema fatorial confiorme GOMES (1985), onde, alem do processo de proteça (ensacamento ou nao) das paniculas, compararam-se tambem os três periodos de avaliaçă dos dois clones.

o efeito ou nå dos clones com relaça ao processo de proteçáo (ensacamento ou nå) foi avaliado através de uma análise conjunta dos dois experimentos. 
Esse modelo estatistico permitiu também avaliar-se o número de frutos fixados nas dez árvores selecionadas de cada clone, os horários de maior concentraçao de visitar as paniculas, e o efeito do ensacamento ou nå, na fixaçă dos frutos.

Para as análises da variancia das variaveis estudadas, com exceçăo da variável duraça de visitas, as demais foram transformadas para $\sqrt{x+0,5}$, conforme STEEL \& TORRIE $(1960)$.

As médias de duraça de visitas, do número de frutos fixados foram comparadas pelo teste de Tukey e de peso de fruto pelo teste "t" de Student, ambos a $5 \%$ de probabilidade. 


\section{REsultados e discussåo}

\subsection{Teste de polinizaçao}

\subsubsection{Insetos visitantes}

Ordem Hymenoptera

Superfamilia Vespoidea

Familia Vespidae

Saa individuos que se caracterizam por apresentarem reentrâncias na margem interna dos alhos compostos. Formam sociedade ande as castas sao formadas pelas raintias, machos e operárias, que sao mais ou menos semelhantes. Muitas formas adultas alimentam-se de substâncias açucaradas e larvas de outros insetos que saro capturados e triturados pelos adultos. Us ninhos, saao feitos de fibra vegetal misturada com saliva. Apreseritam como gêneros mais importantes os gêneros Polystes e Polibia, cujos ninhos sào abertos e fechados, respectivamente.

Especies coletadas:

Palybia ignobilis (Haliday, 1936)

Brachygastra lecheguana (Latreille, 1824) 
Palybia sp.
Zettus sp.
Polistes sp.

Supertamilia Formicoidea

Familia Formicidae

Subfamilia Formicinae

Saro formigas que apresentam peciolo com um segmento, sem ferrao e abertura anal circular. Estes individuos preferem liquidos açucarados para sua alimentaçă embora podemos encontrar alguns deles insetivoros. Essas formigas foram comumente encontradas em constante movimento no tronco das árvores de cajueiro, como também nas paniculas.

Especie coletada:

Camponatus sp.

Superfamilia Apoidea

Compreende os himenopteros conhecidos por abel has e mamangavas.

Familia Apidae

A principal caracteristica desta familia é a presença de curbicula na parte externa das tibias posteriores, usada para o transporte de polen.

Subfamilia Apinae

Nesta subfamilia encontram-se as abelhas do gênero Apis, com várias subespécies, tais como: A. mellifera 
mellifera L. (europeia), A. mellifera ligustica (italiana) e A. mellifera scutellata L. (africana).

$$
\text { Essas abelhas apresentam comportamento }
$$

altamente social, formam uma sociedade onde existe uma só rainha, vários zangöes e as operárias. Apresentam caracteristicas biologicas desejáveis para que sejam manejadas racionalmente pelo homem, com a finalidade de produzir mel e realizar polinizaçăo nas plantas superiores com estruturas florais adequadas para esse fim.

Durante as observaçes de campo, hibridos desse gênero apresentaram-se em maior número e com maior constância de visitas às flores.

Especie coletada:

Apis mellifera L.

Familia Anthophoridae

Subfamilia Anthophorinae

Esta subfamilia e representada por abelhas solitarias, geralmente de conformaça robusta, de tamanho médio, com a corpo coberto de densa pilosidade, e, a presença de escopas e esporaro nas tibias posteriores. As espécies do gênero xylocopa såo contiecidas como mamangavas. 
Especies coletadas:
xylocopa (Neoxylocopa) grisescens Lep., 1841
xylocopa (Neoxylocopa) cearensis Ducke, 1910

Ordem Diptera

Superfamilia Syrphoidea

Familia Syrphidae

Ocorrem em quase todas as lugares, com especies e habitats diferentes. Os adultos sao na maioria das vezes encontrados em lugares onde existem flores $e$ com frequência pairam longamente no ar. Muitos tem cores vivas e assemelham-se a diversas abelhas, havendo especies bastante semelhante à abelha doméstica.

Especie coletada:

arnidia obesa

Ordem Hemiptera

Subfamilia Pyrrhocoridae

sao percevejos pequenos, desprovidas de ocelos e com nervuras anastomosadas na base das partes membranosas dos hemielitros.

\footnotetext{
Espécie coletada:

Dysdercus sp.
}

Afora os taxons descritos anteriormente e apresentados na Tabela 3, verificou-se a presença de vários lepidopteros visitando as paniculas nos horarios mais quentes do dia. 
Tabela 3. Taxons capturados nas inflorescências de cajueiro no periodo de agosto a setembro. Pacajus (CE), 1991 .

Ordem/Familia Taxons

Hymenoptera

Vespidae

Brachygastra lecheguana

(Latreille, 1824)

Polybia ignobilis Haliday, 1936

Palybia sp.

Zethus SP.

Palistes sp.

Formicidae

Camponotus sp.

Apidae

Apis mellifera L.

Anthophoridae

Xylacapa (Neoxylocopa) grisescens LeP., 1841

Xylocopa (Neoxylocopa) cearensis

Ducke, 1910

Diptera

Syrphidae

Arnidia obesa

Hemiptera

Pyrrhocoridae

Dysdercus sp. 
Dos taxons apresentados na Tabela 3 , apenas A. mellifera e Campanatus 5p. fizeram-se presentes em maior número e com maior constancia durante os periodos de observaçă, sendo as demais especies raramente encontradas e em número bastante reduzido. Essas espécies são consideradas como. visitantes ocasionais, que do ponto de vista da polinizaça nå sào consideradas importantes para a cultura. Wultrath \& Speck:, citado por MCGREGOR (1976b) afirmam que as abelhas sao atraidas durante todo o dia pela riqueza do nectar das flores. FREE \& WILLIAMS (1976) verificaram a presença de abelhas, formigas e dipteros realizando polinizaçă nas flores, sendo que BARROS (1988a) verificou a presença de formigas pretas e abelhas visitando flores de cajueiro, na regiào litorânea do nordeste brasileiro. Já, BISPO \& COSTA (1991) verificaram em seus resultados preliminares que dentre os taxons capturados nas paniculas de cajueiro na Bahia, havia tambem a presença de Apis mellifera, embora nao havendo coincidencia para os demais taxons capturados.

Outros autores tambem :verificaram, a presença de formigas visitando as paniculas de cajueiro, conforme os trabalhos de RAO \& HASSAN (1957); NORTHWOOD (1966) e FREE \& WILLIAMS (1976) na India, Tanzania e Quênia, respectivamente.

\footnotetext{
WWLLFRATH, A. \& SPECK, J.J. La flora mellifera. 2.ed. Méxica, Ediçôs Mexicanas, 5.d. 96p. (Enciclopedia apicola, 28).
} 


\subsubsection{Horário e numero de visitas}

Conforme as observaçoes de campo realizadas no periodo de florescimento da cultura, as abelhas do gênero Apis foram as insetos predominantes como visitantes das paniculas. Assim, as observaçoes com relaça ao horário e número de visitaș, foram feitas em relaçăo ao grupo citado, muito embora, os demais insetos tenham sido avaliados, com exceçăo das formigas pretas (Camponotus sp.), que se apresentam em pequeno número.

A baixa freqüencia de outras especies provavelmente deve-se d ausincia de áreas cam reservas de matas nas proximidades. Por outro lado, há de considerar-se o uso de defensivos agricolas nas areas experimentais próximas.

Em relaça à plantas em florescimento, vale ressaltar que no periodo de julho/agosto, as abelhas encontravam-se visitando flores de vassourinha-de-botao (Borreria 5p.), especie nativa que vegeta no periodo chuvoso e representa uma boa fonte nectarifera para as abelhas. De certo modo, as abelhas preferem essa especie em detrimento da flor de cajueiro, provavelmente pelà maior conicentraçao de açúcares no néctar e quiça, também pela maior abundancia. Nao obstante, como a florada dessa especie já se encontrava no seu término, logo, as abel has passaram a visitar as flores do cajueiro, tendo no entanto, essa espécie passado a constituir-se, praticamente, a única fonte de alimento disponivel no campo. 
As abelihas, geralmente realizavam visitas individuais as paniculas, tendo no entanto, sido observado, que quando mais de uma abelha visitava a mesma panicula, na maioria das vezes, elas dispersavam-se no momento que entravam em contato. Tal fato, tambem explica o pequeno número de outras especies visitantes. As visitas, muitas vezes; foram prejudicadas pela afăo do vento, que obrigava as abelhas a transferirem-se rapidamente para outras paniculas. Durante as observaçees, verificou-se que houve uma variaça do número de visitas em relaço as paniculas observadas. Isto provavelmente tenta ocorrido em funcao da variaçăo do número de flores abertas e da idade dessas. Segundo GIORGINI \& GUSMAN (1972) há influência na secreça do nectar, sendo a máxima secrecao verificada na época da maturidade do ovário lque decresce acentuadamente apos a fecundaçăo) e tambem, o sexo e as condiçes edafoclimaticas.

Atraves da Tabela 4 observa-se que houve significãncia ao nivel de $1 \%$ de probabilidade para horario de visitas. Pela Tabela 5, observa-se que o primeiro pico de visitas ocorre entre $9 h$ e $11 \mathrm{~h} 30$ e um segundo no periodo de 12 hoo as 14 h3o (Figura 1), que coincide com a abertura das flores, que segundo NORTHWOOD (1966) ocorre entre 11 hoO e 12h30, ou ainda de acordo com RAO \& HASSAN (1957); NAIR (1979) e NAIR (1980), que relataram uma concentraça de aberturas de flores entre 10 hoo e 12 hoo. 
Tabela 4. Fontes de variaçao, graus de liberdade (GL), quadrados medios (GM) e significancia do número (NU) e duraço das visitas (DV) de abelhas as paniculas de cajueiro-anao-precoce, clone ccP-06. Pacajús (CE), 1991).

Fonte de Variaçào

Arvores

Horário de visita

Residuo
GL

$Q M(N U)^{2}$

QM(DV)

C.V. (\%)

14,51

$6,1067 *$

6

3,019 ns

2,43722

3

$89,3385 * *$

2,4481

18

1,6817

1 Dados transformados para $\sqrt{x+0,5}$.

* Diferença significativa ao nivel de $1 \%$ de probabilidade.

* Diferença significativa ao nivel de $5 \%$ de probabilidade. ns Nao significativo ao nivel de $5 \%$ de probabilidade.

Tabela 5. Médias do número e duraçăo das visitas (s) de abelhas (Apis mellifera L.), as paniculas de cajueiro do clone CCP-O6, em diferentes horários. Pacajús (CE), 1991.

\begin{tabular}{|c|c|c|}
\hline $\begin{array}{l}\text { Visita } \\
\text { Horarios }\end{array}$ & $\begin{array}{l}\text { Número de } \\
\text { visitas* }\end{array}$ & $\begin{array}{c}\text { Duraça de visi- } \\
\text { tas (segundos) }\end{array}$ \\
\hline O6h as 08h30 & $6,36 \subset$ & $9,78, a$ \\
\hline o9h as $11 \mathrm{~h} 30$ & 13,96 a & 9,30 a \\
\hline $12 \mathrm{~h}$ as $14 \mathrm{~h} 30$ & $8,99 \quad b$ & 10,45 a \\
\hline $15 \mathrm{~h}$ as $17 \mathrm{~h} 30$ & $6,41 \mathrm{c}$ & $10,55 a$ \\
\hline
\end{tabular}

* Medias sequidas da mesma letra, na vertical, nao difere estatisticamente entre $5 i$, ao nivel de $5 \%$ de probabilidade, pelo teste de Tukey.

Para análise estatistica, os dados foram transformados em $\sqrt{x+0,5}$. 
BISPO \& COSTA (1991) relataram que na Bahia o maior número de espécies em panicula do cajueiro, foi encontrado no periodo entre 10 hoo e 12 hoo.

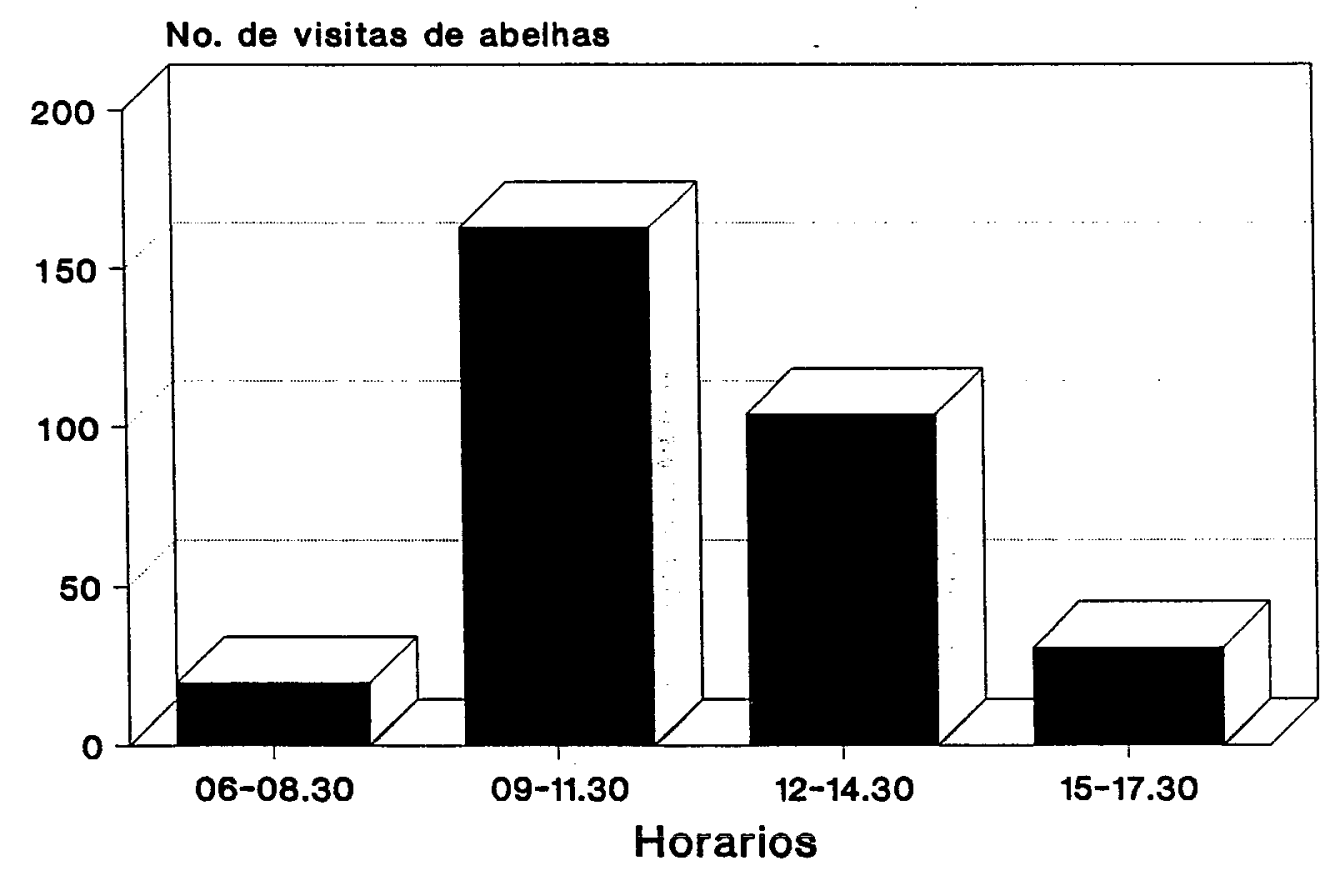

Figura 1. Medias do número de visitas de abelhas (Apis mellifera $L$.$) as paniculas de cajueiro-anao-$ precoce, do clone CCP-Ob em diferentes horários. Pacajus (CE), 1991. 


\subsubsection{Duraçăo das visitas}

As visitas de abeihas A. mellifera às paniculas, tiveram uma duraçăo muito variável de 5 até 90 segundos, apresentando uma média de aproximadamente 10 segundos para os horários de observaçao.

Pelos resultados da tabela 5 , citada anteriormente, verificou-se que nao há diferença significativa de duraçăo dessas visitas, embora a maior duraçă tenta acorrido nos dois ultimos periodos, como podemos observar pela mesma tabela e graficamente pela Figura 2.

MLGREgor et al. (1965) obteve uma media de 10 segundos para flores de melar cantalup. Já em girassol, a média foi de 140 a 170 segundos, respectivamente, para coleta de nectar e polen (MORETTI, 1989).

Na literatura năo existe informaçoes a respeito da duraçá de visitas de abelhas do gênero Apis em panicula de cajueiro, no entanto, acreditamos que esse fato esteja relacionado com fatores pre-florais e que agem durante a floraçăo. 


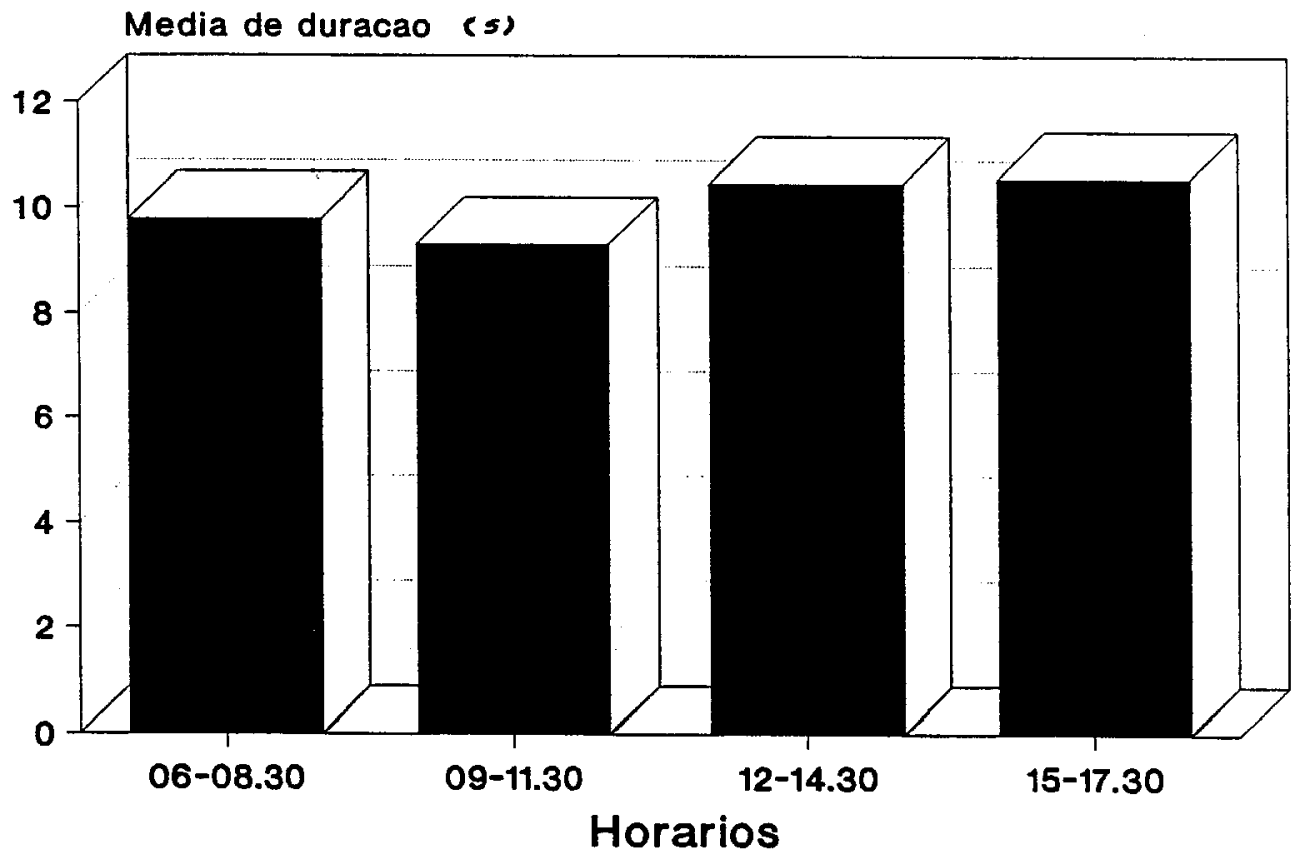

Figura. 2. Médias de duraçao das visitas de abelhas (Apis mellifera) à paniculas de cajueiro anaoprecoce, clone CCP-O6 em diferentes. horários. Pacajus (CE), 1991.

\subsubsection{Número de frutos fixadas}

Ds resultados pertinentes ao número de frutos fixados, bem como os das análises estatisticas sao apresentados nas Tabelas 6,7 e 8 , respectivamente. 
Tabela 6. Fontes de variaçăo, graus de liberdade (GL), quadrados medios (QM) e significancia para numero de frutos fixados por paniculas ensacadas e nao ensacadas de dois clones de cajueiro anao-precoce. Pacajus (CE), 1991.

\begin{tabular}{|c|c|c|c|}
\hline \multirow{2}{*}{ Fonte de Variação } & \multirow{2}{*}{ GL } & \multicolumn{2}{|c|}{ QM } \\
\hline & & CCP-O6 & CCP-76 \\
\hline Periodb de avaliaça & 2 & $18,0820 * *$ & $15,0832 * *$ \\
\hline Proteça & 1 & $114,4868 * *$ & $104,7615 * *$ \\
\hline Arvore & 9 & 1,2510 ns & $0,3186 n 5$ \\
\hline Proteçăo x árvore & 9 & $0,6620 n 5$ & $0,2912 n s$ \\
\hline Residuo & 38 & 1,0228 & 0,4292 \\
\hline C.V. (\%) & & 40,87 & 25,58 \\
\hline
\end{tabular}

* Dados transformados para $\sqrt{x+0,5}$

** Diferença significativa ao nivel de $1 \%$ de probabilidade.

ns Diferença nao 5 ignificativa ao nivel de $5 \%$ de probabilidade.

Tabela 7. Análise conjunta dos dois experimentos, entre os periodos de avaliaçáa e da proteça das paniculas de cajueiro-anao-precoce, sobre a variável número de frutos fixados. Pacajus (CE), 1991.

\begin{tabular}{lcc}
\hline Fonte de Variaçao & GL & E(QM) \\
\hline Clone & 1 & $0,2224 n s$ \\
Periodo de avaliaçao & 2 & $20,5947 * *$ \\
Proteçăo & 1 & $219,1404 * *$ \\
Arvore & 9 & $0,7415 n s$ \\
Clone x proteçao & 1 & $0,1079 n 5$ \\
Residuo & 105 & 0,9176 \\
C.V. (\%) & & 38,05
\end{tabular}

* Dados tranformados para $\sqrt{x+0,5 .}$

* Diferença significativa ao nivel de $1 \%$ de probabilidade. ns Diferença năo significativa ao nivel de $5 \%$ de probabilidade. 
Tabela 8. Medias do número de frutos fixados em paniculas nao ensacadas e ensacada de dois clones de cajueiro anao-precoce. Pacajus (CE), 1991).

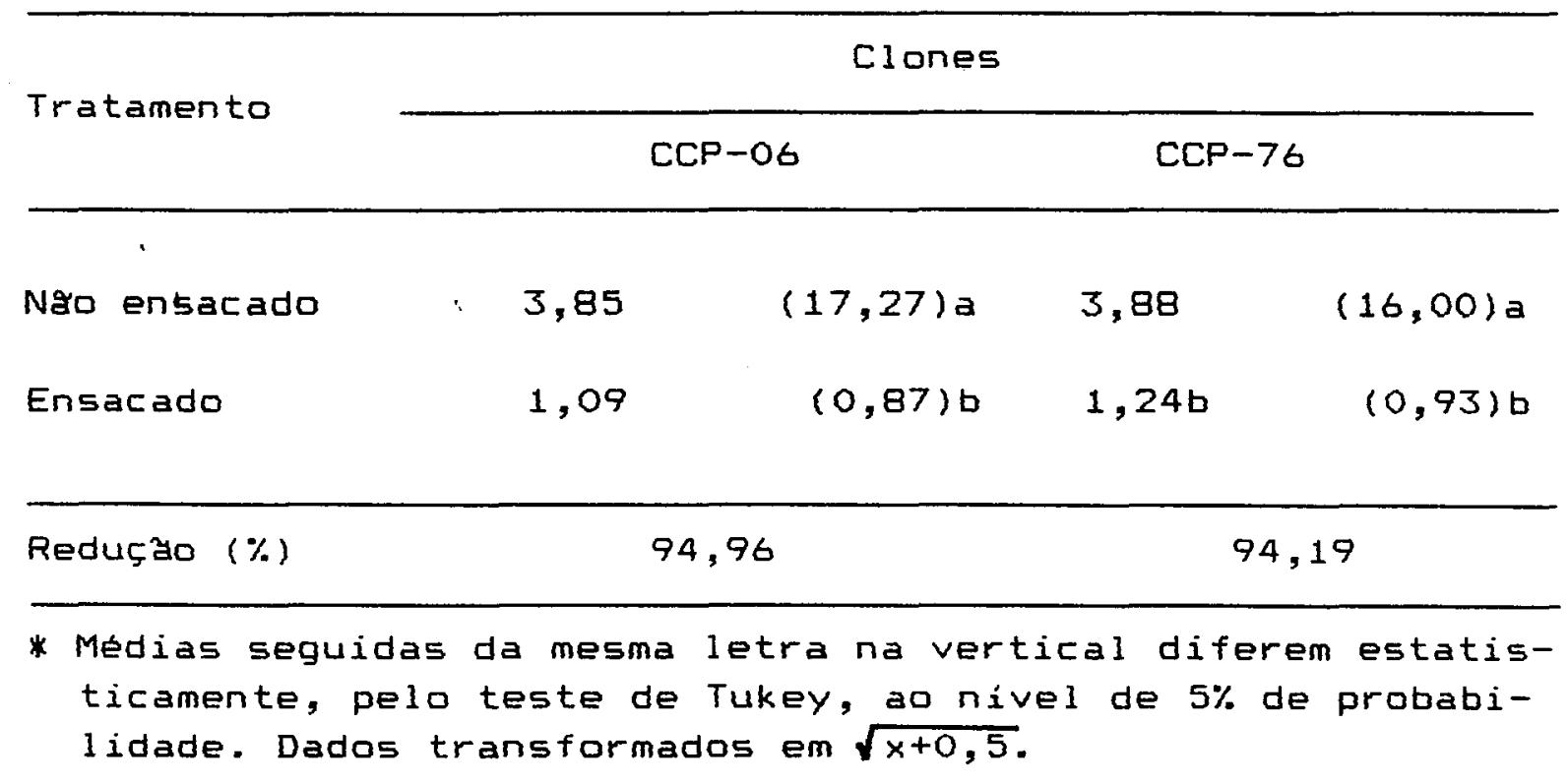

Pelos resultados da Tabela 8 e figura 3 , verifica-se que as paniculas nao ensacadas apresentaram um maior número de frutos fixados que aquelas ensacadas, para os dois clones; as diferenças foram estatisticamente significativas, no entanto, năo ocorreu diferença entre clones (Tabela 7).

O maior número de frutos fixados nas paniculas não ensacadas confirmam a importancia das abelhas como agentes polinizadores para cultura, sendo o mesmo verificado por FREE \& WILLIAMS (1976) usando a mesma metodologia em cajueiro do tipo comum na Jamaica. 


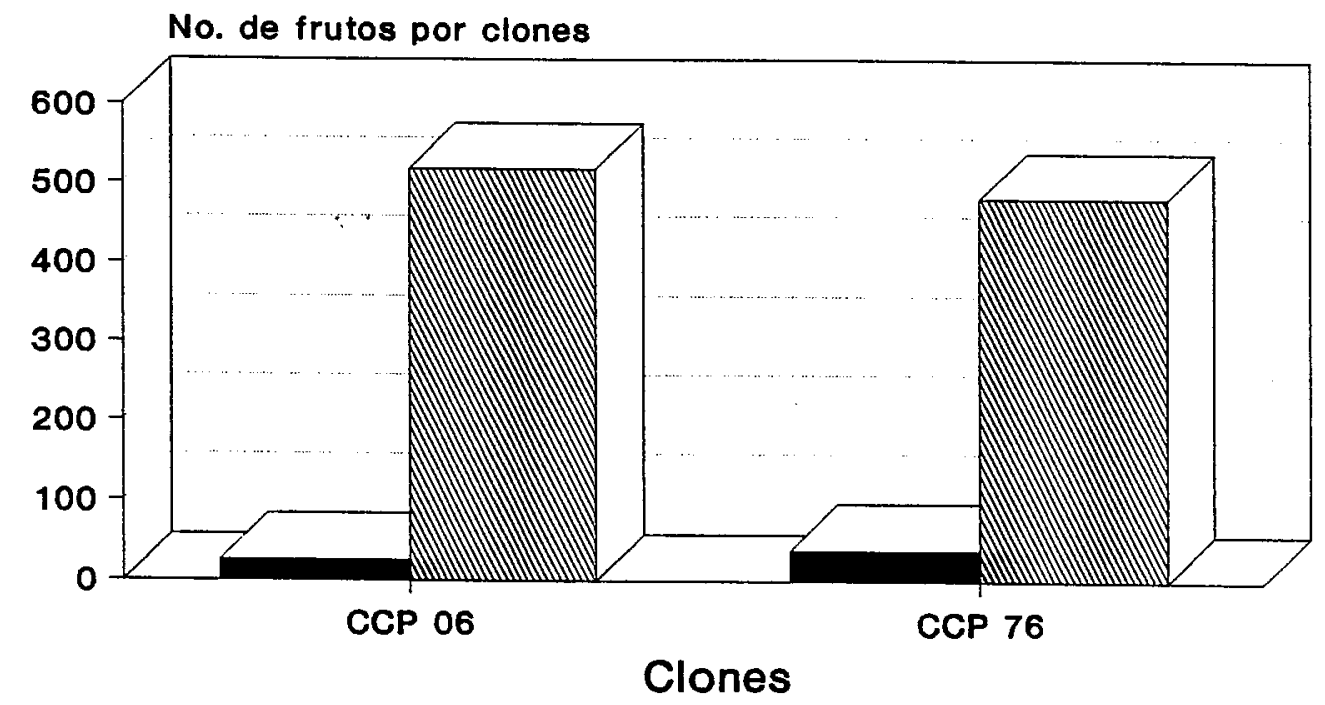

Ensacada Nao ensacada

Figura 3. Médias do numero de frutos fixados em paniculas ensacadas e naro ensacadas de dois clones de cajueiro anăo-precoce. Pacajus (CE), 1991.

RAO \& HASSAN, 1957; BINGGER, 1960; DAMODARAN et al., 1966 e NAIR, 1980 afirmaram que a morfologia das flores justifica a polinizaçao entomófila, sendo que NORTHWOOD, 1966 e PURSEGLOVE, 1968 consideraram a polinizaçao entomóila mais importante para o cajueiro, e McGREGOR (1976b) e MEDINA (1978) afirmaram que as insetos, principalmente as abelhas, sáo responsáveis pelo aumento de produçăo. 
Ainda pelas Tabelas 6 e 7 , podemos verificar os efeitos não significativos para interaça clone $x$ proteção, demonstrando que a aço desses dois fatores e totalmente independente. Pelas mesmas Tabelas pode-se verificar, atraves da diferenca nao significativa, que as abelhas visitam aleatoriamente as árvores, por isso, nao há repercussão na fixaçăo de frutos.

\subsubsection{Peso de frutos}

Pela analise da variancia (Tabela 9), verifica-se que houve diferença significativa entre os tratamentos ao nivel de $1 \%$ de probabilidade, sendo verificado pelo teste " $t$ " de Student ao nivel de $5 \%$ de probabilidade (Tabela 10) e representado graficamente na Figura 4.

Tabela 9. Análise da variância do peso (g) de frutos oriundos de paniculas ensacadas $e$ nao ensacadas de dois clones de cajueiro anao-precoce. Pacajus (CE), 1991 .

Causa da Variancia

GL

SQ

QM

F

\begin{tabular}{lrrrr}
\hline Tratamentos & 3 & 167,9470 & 54,9834 & $81,49 * *$ \\
Residur & 84 & 56,6777 & 0,6747 &
\end{tabular}

Total

$87 \quad 221,6270$

C.V. (\%) 11,63

** Significativo ao nivel de $1 \%$ de probabilidade. 
Tabela 10. Medias do peso ( $g$ ) dos frutos oriundos de paniculas ensacadas e nao ensacadas, de dois clones de cajueiro anao-precoce. Pacajus (CE), 1991 .

\begin{tabular}{lll}
\hline Tratamentos & CCP-76 & CCP-06 \\
\hline Nå ensacado & 8,58 a & 6,63 c \\
Ensacado & 7,68 b & 4,88 d \\
\hline Reduçă $(\%)$ & 7,25 & 26,40 \\
\hline
\end{tabular}

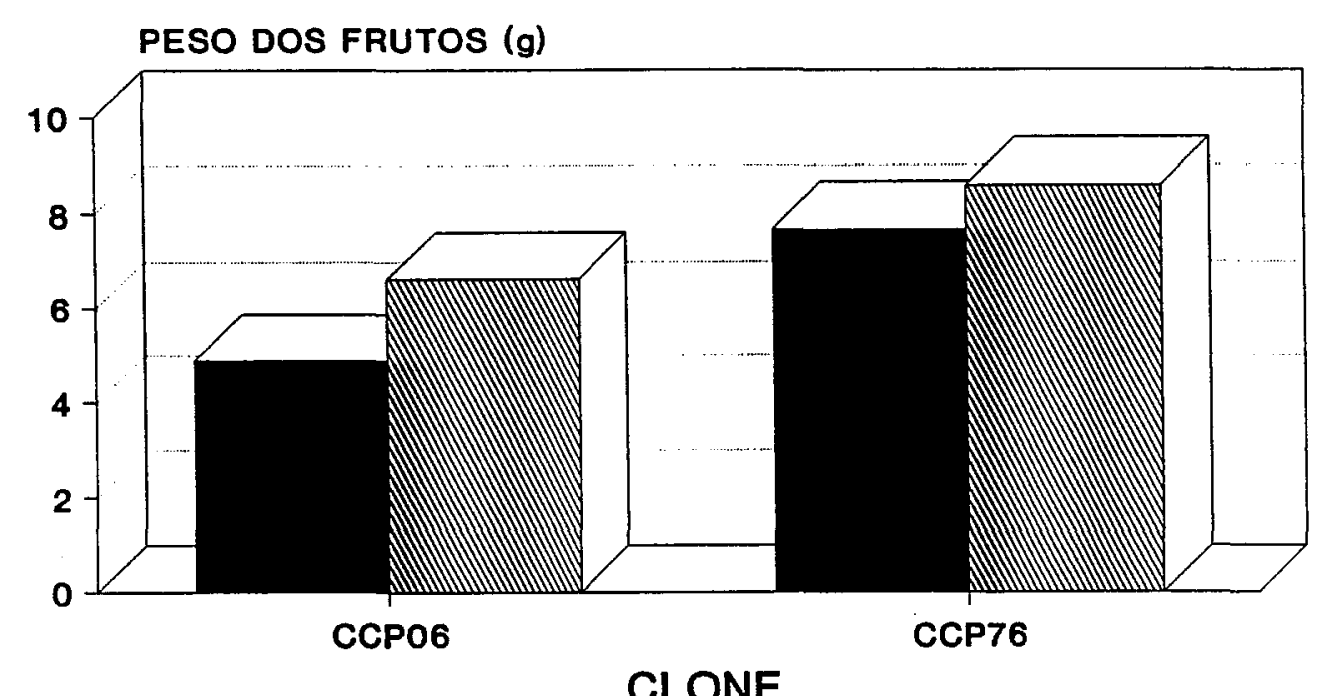

\section{CLONE}

\section{ENSACADOS NAO ENSACADOS}

Figura 4. Médias do peso ( $g$ ) de frutos colhidos em paniculas ensacadas e nao ensacadas de dois clones de cajueiro-anao-precoce. Pacajus (CE), 1991. 
Quando compara-se as médias dos pesos dos frutos colhidos em paniculas nao ensacadas e ensacadas para os dois clones, verifica-se que os frutos oriundos de paniculas naro ensacadas apresentaram medias de peso maior (Tabela 10 e Figura 4) citadas anteriormente.

A diferença em favor dos frutos nåo ensacados pode ser atribuida a diferença no indice de polinizaça devido ao livre acesso das abelhas, a que provavelmente influenciou a manifestaçao de fatores fisiológicos da planta. Estes resultados sao semelhantes aos obtidos com forrageiras leguminosas, abóbora e aqüênio de girassol, segundo NOGUEIRA \& PEREIRA (1983), ÁvILA et al. (1989) e MORETI (1989), respectivamente.

\subsubsection{Composiçao centesimal dos frutos}

Pela Tabela 11, verifica-se que a clone CCP-O6 foi o que apresentou maior variạ̧a na composiça com relaça ao tipo de polinizaçăo ocorrendo um aumento no teor de proteina e carboidratos, em detrimento dos teores de cinza e de oleo, quando as paniculas foram isoladas. Já o.clone CCP76, nao foi tao influenciado, pois apresentou teores de bleo, proteina bruta e cinzas variavel com o tipo de polinizaça.

Pela literatura, verifica-se que os teores de dleo, proteina e carboidratos sao semelnantes áqueles determinados por TREVAS FILHO, $1971 \mathrm{em}$ cajueiro do tipo comum 
nåo polinizado. MORETI et al., 1987 verificaram um menor teor de oleo em gergelim (Sesamum orientalis) quando as plantas foram isoladas dos insetos.

Tabela 11 . Composiçao centesimal (\%) de amêndoa de castanta de caju "in natura", oriundas de paniculas ensacadas e nao ensacadas de dois clones de cajueiro anao-precoce.

\begin{tabular}{lcccc}
\hline \multirow{2}{*}{ Clones } & \multicolumn{2}{c}{ Ensacadas } & Nao ensacadas \\
\cline { 2 - 5 } Componentes & CCP-76 & CCP-06 & CCP-76 & CCP-06 \\
\hline Gleo & 49,9 & 48,2 & 48,8 & 51,4 \\
Proteina bruta & 30,3 & 30,3 & 31,9 & 28,0 \\
Cinzas & 2,8 & 2,8 & 2,9 & 3,2 \\
Carboidratos & 17,0 & 18,5 & 16,4 & 17,4 \\
\hline
\end{tabular}




\section{CONCLUSÖES}

Baseando-se nos resultados obtidos na presente pesquisa, conclui-se que:

- Apis mellifera é a especie mais importante na polinizaçăo da cultura;

- A menor fixaça de frutos ocorre nas paniculas isoladas independentemente do clone;

- A duraça média de visitas de Apis mellifera ás paniculas é de 10 segundos;

- A Apis mellifera apresenta um pico máximo de visitas as paniculas das 9 as $14 h 30$;

- Paniculas isoladas apresentaram um menor peso de frutos para ambos os clones;

- 0 clone CCP-Ob apresenta maior variaça qualitativa dos frutos com o tipo de polinizaçă; .

- Paniculas isoladas do clone CCP-Ob, apresentaram frutos com menores teores de cinza, dleo e maiores teores de proteina e carboidratas. 


\section{REFERENCIAS BIBLIOGRÁFICAS}

AMERICAN OIL CHEMISTS' SOCIETY. Official and tentative methods. 3.ed. Champaign, 1983. n.p.

ANUARIO ESTATISTICO DO BRASIL - 1991. Rio de Janeiro, $\mathbf{5 1 :}$ $504,1991$.

ARGLES, G.K. Anacardium dentale. Cashew. In:

The propagation of tropical trees. Farntiam Royal, CAB, 1976. p.182-222. (Horticultural Review, 4).

ASSOCIATION OF OFFICIAL ANALYTICAL CHEMISTS. Microchemical methods. In: Official methods of analysis. Arlinton, 1990. v.1, cap. 12, p.337-48.

ÁVILA, J.C.; MARTINHO, M.R.; CAMPOS, J.P. Polinizaçăo polinizadores na produçao de frutos e sementes hibridas de abobora (Cucurbita pepo var. melopepo). Anais da Sociedade Entomológica do Brasil, Jaboticabal, 18(1): $13-9,1989$.

BARROS, L.M. Origem, dispersto e perspectivas de melhoramento do cajueiro (Anacardium occidentale L.). Piracicaba, ESALQ/Depto. de Genetica, 1987. 36p. 
BARROS, L.M. Biologia floral, colheita e rendimento. In: LIMA, V.P.M.S., org. A cultura do cajueiro no nordeste do Brasil. Fortaleza, BNB, 1988a. P.301-19. (Estudos Econômicos e Sociais, 35).

BARROS, L.M. Melhoramento. In: LIMA, V.P.M.S., org. cultura do cajueiro no nordeste do Brasil. Fortaleza, BNB, 1988b. P.321-56. (Estudos Econômicos e Sociais, 35):

BARROS, L.M. Caracterizaçăo morfológica e isoenzimática do cajueiro (Anacardium occidentale L.), tipos comum e anao precoce, por meio de tecnicas multivariadas. Piracicaba, 1991. 256p. (Doutorado - Escola Superior de Agricultura "Luiz de Queiroz"/USP).

BARROS, L.M. \& MELO, Q.M.S. Alguns aspectos sobre a cultura do caju (Anacardium occidentale L.). Revista Brasileira de Fruticultura, Cruz das Almas, 9: 29-38, 1987.

Barros, L.M.; ARAUJo, F.E. de; ALMEIDA, J.I.; TEIXEIRA, L.M.J. A cultura do cajueiro anáo. Fortaleza, EPACE, 1984. 64p. (EPACE. Documentos, 3).

BINGGER, M. Selenothrips rubrocinctus (Giard) and the floral-biology of cashew in Tanganyika. East African Agricultural Journal, Nairobi, 25(4): 229-34, 1960.

BISPO, S.W.P. \& COSTA, J.N. Insetos polinizadores potenciais do cajueiro no Nordeste da Bahia- Fortaleza, EMBRAPA/CNPCa de Caju, 1991. 3p. (EMBRAPA/CNPCa. Pesquisa em Andamento, 5). 
COPELAND, H.F. Observations on the reproductive structures of Anacardium occidentale L. Phytopmorphology, New Delti, 11(4): 315-24, 1961 .

CRANE, E. o livro do mel. Sao Paulo, Nobel, 1983. 255p.

DAMODARAN, V.K.; ABRAHAN, J.; ALEXANDER, K.M. The morphologY and the biology of cashew flower II - Anthese, Dehiscence, recepitivity of stigma, pollination, fruit set and fruit development. Agricultural Research Journal, Kerala, 4(2): 78-84, 1966 .

EMPRESA BRASILEIRA DE PESQUISA AGROPECUÁRIA. Plano de implantaçao do Centro Nacional de Pesquisa do Caju. Brasilia, 1987. 53p.

EMPRESA BRASILEIRA DE PESQUISA AGROPECUÁRIA. Centro Nacional de Pesquisa do Caju. Relatório técnico anual do Centro Nacional de Pesquisa do Caju, 1987-1988. Fortaleza, 1990. $88 p$.

FALUYI, M.A. The natural breeding system of cashew (Anacardium occidentale L.) and its influence on yield in Southwestern Nigeria. Nigeria Journal Science, Ibadan, 17(1): 51-60, 1983 .

FAO PRODUCTION YEARBOOK - 1991, ROME, 45: 172, 1992.

FREE, J.B. Introduction. In: Insects pollination crops. London, Academic Press, 1970a. cap. 1, p.1-11.

FREE, J.B. Anacardiacea. In: _- Insects pollination crops. London, Academic Press, 1970b. cap. 14, p.193-7. 
FREE, J.B. \& WILLIAMS, I.H. Inserts pollination of Anacardium occidentale (L.), Blighia sepids Roening and Persea americana Mill. Tropical Agricultural, Trindade, $53(2): 125-39,1976$.

GIORGINI, J.F. \& GUSMAN, A.B. A importancia das abelihas na polinizaçăo. In: CAMARGo, J.M.F. Manual de apicultura. Sao Paulo, Agronâmica Ceres, 1972. P.155-64.

GOMES, F.P. A estatistica moderna na pesquisa agropecuária. 2.ed. Piracicaba, POTAFOS, 1985. 162p.

HARLAN, J.R. \& WET, J.M.J. On the quality of evidence for origem and dispersal of cultivated plants. Current Anthropology, Chicago, 14(1/2): 51-5, 1973 .

IMPORTANCIA da polinizaçaro. Apicultura no Brasil, sao Paulo, 3(16): 23, set./out. 1986.

JOHNSON, D.V. The botany origin and spread of the cashew (Anacardium occidentale L.). Journal of Plantation Crops, Kasaradog, 1(1): 1-7, 1973 .

JOHNSON, D.V. Botânica e biologia do caju. In: - $\mathbf{0}$ caju do nordeste do Brasil; um estudo geografico. Fortaleza, Banco do Nordeste do Brasil/ETENE, 1974. P.1921.

KERR, W.E. \& AMARAL, E. Apicultura cientifica e prática. Så Paula, Secretaria de Estado dos Negócios da Agricultura do Estado de Saro Paulo, 1960. 148p. 
LIMA, V.P.M.S. Origem e distribuiçăo geográfica. In: , org. A cultura do cajueiro no nordeste do Brasil. Fortaleza, BNB, 1988. P.3.13. (Estudos Econômicos e Sociais, 35).

LOPES NETO, A. A agroindústria do cajú no Nordeste do Brasil e en outros paises grandes produtores. Fortaleza, Banco do Nordeste do Brasil, 1981. 472p.

MARTINHO, M.R. A criaçă de abelhas. 2.ed. Saro Paulo, Globo, 1989. 180p.

MEGRECOR, S.E.; LEVIN, M.D.; FORSTER, E.R. Honey bee visitors and fruit set of cantaloups. Journal of Econamic Entomology, Lantian, 58(5): 968-70, 1965.

MCGREGOR, S.E. Economics of plant pollination. In: Insect pollination of cultivated crops plants. Washington, USDA/ Agricultural Research Service, 1976. p.1-7 (USDA/ARS. Agriculture Handbook, 496).

McGREGOR, S.E. Cashew. In: - Insect pollination of cultivated crop plants. Washington, USDA/Agricultural Research Service, 1976. P.130-2. (USDA/ARS. Agriculture Handboook, 496).

MEDINA, J.C. Cultura. In: MEDINA, J.E.; BLEINROTH, E.W.; BERNHARDT, L.W.; HASHIZUME, T.; RENESTO, O.V.; VIEIRA, L.F. Caju; da cultura ao processamento e comercializaça. Campinas, ITAL, 1978. cap. 1, p.5-66.

MITCHELL, J.D. \& MORI, S.A. The cashew and its relatives (Anacardium: Anacardiaceae). Memoirs of the New York Botanical Garden, New York, 42(1): 1-76, 1987. 
MORETI, A.C.C.C. Estudo sobre a polinizaçăo entomófila do girassol (Helianthus annuus L.) utilizando diferentes métodos de isolamento de flores. Piracicaba, 1989. 126p. Loutorado - Escala Superior de Agricultura "Luiz de Gueiroz"/USP).

MORETI, A.C.C.C.; MARCHINI, L.C.; REGITANO-D'ARCE, M.A.B. Observaçôs sobre a polinizaçăo entomofila do gergelim (Sesamum orientalis). In: CONGRESSO BRASILEIRO DE ENTOMOLOGIA, 1.; ENCONTRO SOBRE MOSCAS-DAS-FRUTAS, 1. , Campinas, 1987. Resumos. Campinas, IAC, 1987. V.1, P. 78 .

MORTON, J.F. The cashew's brighter future. Economic Botany, New York, 15(1): 57-78, 1961.

MOTA, M. Origem. In:

0 cajueiro nordestino.

3.ed. Recife, Fundação de Cultura Cidade do Recife, 1982. p.39-44. (Coleçăo Recife, 29).

NAIR, G.S. Floral biology and hybrydization technique in Cashew. Indian Cashew Journal, Cochin, 12(3): 15-7, 1980.

NAIR, M.K.; RAO, E.V.V.B.; NAMBIAR, K.K.N.; NAMBIAR, M.C. In: Cashew (Anacardium occidentale L.). Kerala, Central Plantation Crops Research Institute, 1979. P. 16-26.

NOGUEIRA, R.H.F. \& PEREIRA, J.M.S. Polinizaço entomófila em Glycine wightil (soja perene). In: REUIÃo ANUAL DA SOCIEDADE BRASILEIRA PARA O PROGRESSO DA CIENCIA, 35. , Belém, 1983. Resumos. Ciência e Cultura, Suplemento, Sao Paulo, 35(7): 688, jul. 1983. 
NOGUEIRA NETO, P. Polinizaçao das flores. In: _ A criaçă de abelhas indigenas sem ferrao; Meliponinae. sao Paulo, Chácaras e Quintais, 1953. P.13-56.

NORTHWOOD, P.J. Some observations on flowering and fruitsetting in the cashew Anacardium occidentale L. Tropical Agricultural, Trindade, 43(1): 35-42, 1966.

PARAMESWARAN, N.K.:; DAMODARAN, V.K.; FRABHAKARAN, P.V. Relationship between yield and duration of different phases in flower opening in cashew (Anacardium occidentale L.). Indian Cashew Journal, Cochim, 16(4): 15-9, 1983.

PINHEIRO, F.F.M. \& PARENTE, J.I.C. Estudos preliminares sobre a biologia floral do cajueiro (Anacardium occidentale L.), no Ceará. In: CONGRESSO BRASILEIRO DE FRUTICULTURA, 4., Salvador, 1977. Resumos. Salvador, Sociedade Brasileira de Fruticultura, 1977. P.3.

PREGNOLATTO, W. \& PASCUET, E. Determinaçoes gerais. In: , coord. Normas analiticas do Instituto Adolfo Lutz. 3.ed. Sao Paulo, Inst. Adolfo Lutz, 1985. v.1, cap. 4, p.16-76.

PURSEGLQVE, J.W. Anacardiaceae. In: _L Tropical crops. London, Longmans, 1968. v.1: Dicotyledons, p.1832 .

PURSEglove, J.W. Tropical crops. London, Logmans, 1974. V.1: Dicotyledons.

RAO, V.N.M. \& HASSAN, M.V. Preliminares estudies on the floral biology of cashew (Anacardium occidentale L.).

Indian Journal Agricultural Science, New Delhi, 27: 277$88,1957$. 
REDDI, E.U.B. Under - polimation: a major constraint of cashew-nut prodution. Proceedings Indian of the National Science Academy, Pt. B: Biological Sciences, New Delhi, $53(3): 249-52,1987$.

SMITH, F.G. Bee forrage. In: Beekeeping in the tropics. New York, Longmans, 1960. p.63-77.

STEEL,' R.G.D. \& TORRIE, J.H. Principles and procedures of statistics. New York, Jahn Wiley, 1960. 481p.

THORNTHWAITE, C.W. An approach toward a rational classification of climate. Geographical Review, Bratislava, 38: 55- 94, 1948 .

TREVAS FILHO, $v$. Tecnologia dos produtos do pedúnculo do caju. Fortaleza, s.ed., 1971. 101p. (mimeog.). 